\title{
LA CONSTRUCCIÓN DE PIANOS EN VALENCIA HASTA INICIOS DEL SIGLO XX ${ }^{1}$
}

\author{
Victoria Alemany FerRer
}

\begin{abstract}
Resumen:
Hacia 1830 comenzó a generalizarse el uso del piano en Valencia. Uno de los hechos más significativos que marcaron la progresiva y creciente normalización de su utilización en la ciudad fue precisamente la aparición de talleres autóctonos dedicados a la fabricación de pianos. Esos primeros artesanos que, en algunos casos -como por ejemplo, Pedro Gómez-, conocieron los entresijos de la construcción de la novedosa mecánica pianística fuera del país, abrieron sus talleres en la década de 1830 dejando constancia con ello de que ya se iniciaba por entonces en Valencia una demanda local de instrumentos que justificaba suficientemente su labor. Se han obtenido datos de cuatro fábricas de pianos que funcionaron entre 1830 y principios del siglo XX. Dicha documentación constata que los instrumentos valencianos construidos durante aquel período (1830-1915) obtuvieron gran aceptación tanto en el mercado interno como en el foráneo, y consiguieron prestigiosos galardones en exposiciones y muestras nacionales y extranjeras. También se ha facilitado el conocimiento de los sistemas de producción y comercialización de aquellos talleres, y de las características organológicas que poseyeron los pianos valencianos construidos en las diversas épocas; esa información ha ayudado a valorar la función económica y social que tuvo la fabricación valenciana de pianos en el siglo XIX y ha permitido su comparación con la desarrollada en otras provincias españolas durante la misma época.
\end{abstract}

\section{Palabras Clave:}

Valencia, siglo XIX, piano, construcción de instrumentos de tecla, comercio musical, Pedro Gómez, Carreres, Galiana, Rodrigo Ten y Cía.

\begin{abstract}
:
At around 1830 the use of pianos in Valencia becomes widespread. One of the most significant events that marked the progressive and increasing normalization of its use in the city was precisely the appearance of indigenous workshops dedicated to the piano-makings. Those first craftsmen who, in some cases -like for example, Pedro Gómez-, knew the ins and outs of the construction of the novel pianistic mechanics out of the country, opened their workshops in the decade of 1830 putting with it on record that already at that time started a local demand of instruments that justified sufficiently its work. It has been obtained information of four factories that worked between 1830 and the beginning of the 20th century. This said documentation states that the Valencian instruments made during that period (1830-1915) as much obtained great success in the internal market as in the outsider, and obtained prestigious awards in exhibitions and national and foreign displays. Also has provided with the knowledge of the production and marketing systems of those workshops, and of the characteristics that had the Valencian pianos made at the diverse times; that information has helped to value the economic and social function that had the Valencian manufacture of pianos in the 19th century and has allowed its comparison with the developed one in other Spanish provinces during the same time.
\end{abstract}

\section{Key Words:}

Valencia (Spain), 19th century, piano, piano manufacture, musical marketing, Pedro Gómez, Carreres, Galiana, Rodrigo Ten y Cía.

$1 \mathrm{El}$ presente artículo forma parte de mi tesis doctoral, realizada bajo la dirección del Dr. Antonio Ezquerro, a quien agradezco la supervisión del trabajo: -AlemAny FerRer, Victoria: Metodología de la técnica pianística y su pedagogía en Valencia, 1879-1916. Valencia, Universidad Politécnica de Valencia, 2007. 
Según confirman algunos documentos conservados en la actualidad, el piano, al parecer, era un instrumento ya conocido en Valencia desde finales del siglo XVIII. De hecho, una de las primeras actuaciones musicales públicas que contó con la participación del piano quedó reflejada de la siguiente manera en el Diario de Valencia, periódico decano de la ciudad ${ }^{2}$, el 12 de julio de $1797^{3}$.

«Teatro. Hoy en la Casa de Comedias se dará un Concierto compuesto de Arias, Duetos, Tercetos y Conciertos, con el Piano-forte, del famoso Autor Pleyel ${ }^{4}$. Se espera será del agrado de este respetable Público; a las 7 de la tarde».

Desde entonces, el piano continuó introduciéndose progresivamente en el panorama musical local, si bien, como puede observarse en el anuncio siguiente (publicado en 1800) los intérpretes que actuaban en las "sesiones musicales" públicas procedían todavía mayoritariamente de fuera de la ciudad.

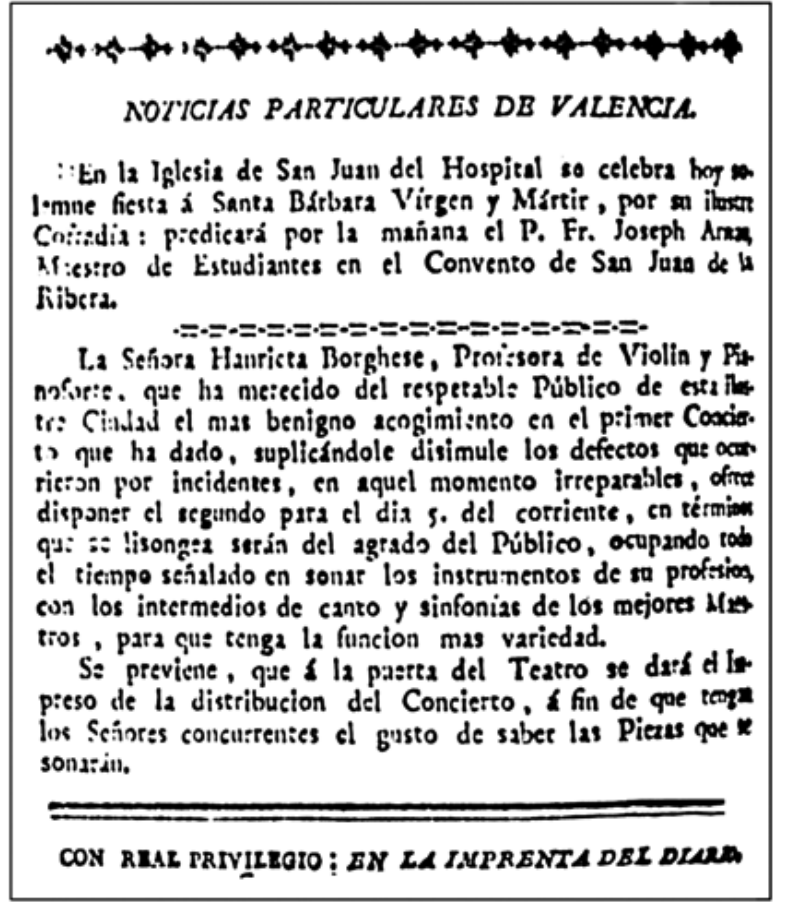

Diario de Valencia. XLII (04.12.1800), p. 264

2 El Diario de Valencia comenzó a publicarse el 01.07.1790.

3 Diario de Valencia (12.07.1797); citado en: -RAMIREZ BENEYTo, Ramón: El compositor Josep Pons i el llenguatge musical per a la litúrgia de l'ordinarium: "Missa a 4 y a 8 con oboes, violines ÿ trompas sobre la antífona Ecce Sacerdos Magnus" (1.786). Tesis Doctoral. Universidad de Valencia, 2004, p. 40.

4 Como es bien sabido, Ignaz Pleyel (*1757; †1831), alumno de Franz Josef Haydn, fue, en vida, uno de los compositores más célebres del momento. Fue autor de numerosos conciertos, música vocal -entre éstas unas Melodien (1793) para voz e instrumento de tecla- y algunas partituras teatrales -Die Fee Urgele oder Was den Damen ge Fäkkt (1776), ópera para marionetas, e Ifigenia in Aulide (1785)-, que, fragmentadas, pudieron ser interpretadas en el concierto celebrado aquel 12.07.1797 en la Casa de Comedias de Valencia. Los famosos pianos Pleyel franceses del siglo XIX fueron fabricados ya por un hijo de Ignaz Pleyel, Camille (*1788; †1855), quien actuó desde 1815 como socio de su padre en los negocios musicales que éste había abierto en París -una editorial, un comercio de música (1795) y una fábrica de pianos (1808)-. 
Respalda también esa idea la Memoria de Instrumentos Músicos que Marcos Antonio de Orellana (*1731; †1813) ${ }^{5}$ remitió en 1800 a la Real Sociedad Económica de Amigos del País en Valencia, actualmente conservada en el Archivo Documental de la citada entidad, pues Orellana menciona allí al fortepiano en los siguientes términos:

«También omito recordar el arpa (instrumento de las más bellas qualidades que pueden imaginarse) que aunque la hemos visto por algunos años arrimada, vuelve a salir, y con mejoras, por industria forastera con el adito [?] del forte-piano».

Por tanto, la circunstancia de que en los dos últimos documentos aparezcan citados intérpretes foráneos o "industrias forasteras" podría corroborar que durante los años de transición al siglo XIX el piano era todavía un instrumento conocido casi exclusivamente por la "alta sociedad valenciana" (la que disfrutaba de un estatus económico que le permitía asistir a aquellos actos musicales públicos) y, por lo tanto, su uso aún no se había generalizado en la ciudad.

Las noticias que incluyen algunas guías de la ciudad de Valencia conservadas actualmente procedentes de la década de 1830, podrían inducir a pensar que el uso del piano comenzó a generalizarse en la ciudad por aquella época. Al parecer, fue entonces cuando los jóvenes valencianos pertenecientes a las clases sociales privilegiadas comenzaron a recibir clases de piano, demostrando con ello que dicho instrumento ya había superado los escenarios y comenzaba a introducirse en determinados hogares.

Como ejemplo, puede citarse la Guía de naturales y forasteros en Valencia y su estado militar de 1830 (Valencia, Imprenta de Benito Monfort, 1830), que ya ofertaba, en su página 148, los servicios de cinco pianistas -u organistas- locales como profesores particulares de "Piano y Música vocal" que, según se detalla en el texto, también impartían clases en "otros colegios de la ciudad". Desgraciadamente, sólo se cuenta actualmente con datos biográficos de dos de ellos: Pascual Pérez, organista de la catedral metropolitana de Valencia ${ }^{6}$, y Salvador Giner, abuelo del célebre Salvador Giner Vidal ${ }^{7}$. De los demás sólo han perdurado sus nombres: Peregrín Vila, José Gubern y Juan Escuder.

5 Jurista y erudito, hermano del también jurista y eclesiástico Francisco Vicente de Orellana $(* 1731 ; \dagger 1813)$. Cursó Filosofía y Leyes en la Universidad de Valencia y se doctoró en la de Gandía. Ejerció como abogado en Cádiz y Madrid, donde se le nombró abogado de los Reales Consejos. En 1780 volvió a Valencia y se dedicó a los estudios históricos y la erudición, aunque continuó ejerciendo su profesión como abogado de la Real Audiencia de la ciudad. Perteneció a varias Academias entre las que destacan la de San Carlos de Valencia y la de San Fernando de Madrid. Sus obras, algunas todavía inéditas y las demás publicadas ya en el siglo XX, concentran diversos estudios sobre la historia de Valencia. Entre ellas destacan Valencia antigua y moderna. Historia y descripción de las calles, plazas y edificios de Valencia (1923); y Biografía pictórica valentina, o vida de los pintores, arquitectos, escultores y grabadores valencianos (1930). Vid.: -MARTinez OrTiz, José: “Orellana Mocholí, Marcos Antonio", en Gran Enciclopedia de la Región Valenciana. Valencia, Graphic 3, 1973, vol. 8, p. 95.

6 Pascual Pérez Gascón (*1802; $\left.{ }^{\dagger} 1864\right)$. Organista y compositor, alumno, entre otros, de José Pons y Francisco Cabo, maestro de capilla, y organista, de la Catedral Metropolitana de Valencia, respectivamente. En 1820 fue nombrado organista de la iglesia de Santo Tomás en Valencia; después, maestro de capilla de la de Villena y en 1830 organista primero de la catedral de Valencia, puesto que desempeñó hasta su fallecimiento. Su interpretación al órgano fue admirada y elogiada por Franz Liszt durante su estancia en Valencia en 1845. Asimismo, fue destacada su faceta pedagógica como coordinador de la docencia musical que realizaba la Real Sociedad Económica de Amigos del País en Valencia, primero en sus escuelas de educación primaria y, a partir de 1850, con la creación de una Escuela Popular de Música dependiente de la citada sociedad. Publicó un Método de solfeo y principios de canto (Valencia, Litografía de N. Sanchís, 1857) que sirvió de texto a muchas entidades que se dedicaron a la pedagogía musical en Valencia durante la segunda mitad del siglo XIX. También editó un Método de armonía (Valencia, Luis Tena, 1866). Alumnos suyos fueron, entre otros, José $\mathrm{M}^{\mathrm{a}}$ Úbeda, Salvador Giner, Eduardo Jiménez y Manuel Penella Raga. Vid. -GALBIS Lopez, Vicente: "Pérez Gascón, Pascual" en Diccionario de la música española e hispanoamericana. Madrid, SGAE, 2000, vol. 8, pp. 647-649; e -ID.: "Id.", en Diccionario de la Música Valenciana. Madrid, Iberautor, 2006, vol.2, pp. 259-261.

7 Primer miembro de una célebre familia de músicos valencianos, padre del violinista Manuel Giner y Roseti, y abuelo de Salvador Giner Vidal, como va dicho. Fue músico mayor de regimiento y director, sucesivamente, de las capillas de música de las parroquias de San Juan, San Andrés y San Martín de Valencia. También destacó en la composición, y ejerció la docencia pianística en el Real 
Pero, el hecho de que el número de docentes particulares de piano que ofrecían sus servicios en la citada guía ya ascendiera a nueve sólo cuatro años después, da muestra del rápido auge que cobró el piano en la ciudad levantina durante la citada década ${ }^{8}$. Por tanto, y teniendo en cuenta ese acusado y progresivo arraigo, no resulta extraño que los datos que confirman el inicio de la factura valenciana de pianos procedan también de esas fechas.

En otras regiones españolas, la manufactura de pianos se había iniciado hacia finales del siglo XVIII y principios del XIX (es decir, antes de 1830 y probablemente, por tanto, antes que en Valencia). Sin embargo, los primeros constructores se habían establecido en la capital española principalmente; de hecho, nunca volvió a repetirse el esplendor alcanzado por los alrededor de veinte talleres madrileños existentes en esa época ${ }^{9}$, entre ellos los de Francisco Flórez, Francisco Fernández $\left(* 1766 ;{ }^{\dagger} 1852\right)$ o Juan Hosseschrueders $(* 1779 ; \dagger 1850)$. También se dieron algunos casos destacados en ciudades de la periferia como, por ejemplo, Sevilla -Juan del Mármol fue un constructor ya bastante especializado ${ }^{10}$, y Zaragoza -en talleres quizá con menor grado de especialización en la construcción de instrumentos con teclado, como fueron los del maestro ensamblador Antonio Enríquez o el maestro carretero Tomás Torrente ${ }^{11}-$.

En general, los pianos españoles construidos en el último cuarto de siglo XVIII y primeros años del siglo XIX se hicieron tomando como base los instrumentos ingleses. Asimismo, la importación de instrumentos hacia España también se realizó principalmente desde Londres (los pianos ingleses que hoy se conservan de esta época están firmados por Johnn Broadwood y Muzio Clementi) ${ }^{12}$, aunque se

Seminario de Nobles (Guía de naturales y forasteros en Valencia y su estado militar. Valencia, Imprenta de Benito Monfort, 1830 , p. 148). Vid.: -Ruz de LiHory, José: “Giner, Salvador”, en La música en Valencia, Diccionario biográfico y crítico. Valencia, Doménech, 1903 , pp.275 y 276.

8 La Guía de naturales y forasteros en Valencia y su estado militar de 1834 (Valencia, Imprenta de Benito Monfort, 1834) menciona a los cinco profesores que ya aparecían en el ejemplar de 1830 (Pascual Pérez Gascón, Salvador Giner, Peregrín Vila, José Gubern y Juan Escuder) y además, a José Ferrís, Francisco Grossi, Juan Oliva -que también se anuncia como afinador de pianos-, y José Valero $\left({ }^{\dagger} 1868\right)$, famoso director y compositor de música escénica en aquella época, quien, además de anunciarse como profesor de piano y música vocal, también se ofrecía allí como enseñante de flauta (también autor de un desaparecido Método para piano-forte (1845) del cual actualmente sólo se conservan referencias bibliográficas. Vid.: -GALBIS LoPEz, Vicente: "Valero Peris, José”, en Diccionario de la Música Valenciana. Madrid, Iberautor, 2006, vol.2, pp. 542-543).

9 Vid. -Bordas IBANeZ, Cristina: "Piano. IV. Siglos XIX y XX", en Diccionario de la música española e hispanoamericana. Madrid, SGAE, 1999, vol. 8, p. 759, donde la autora da el nombre de los fabricantes de pianos establecidos en Madrid antes de 1830.

10 Vid.: KenYon de Pascual, Beryl: "Mármol. 1. Juan [del]”, en Diccionario de la música española e hispanoamericana. Madrid, SGAE, 2000, vol. 7, pp. 196-197.

11 -EzQuerro Esteban, Antonio: "Nuevos datos para el estudio de los músicos Nebra en Aragón”, en Anuario Musical, 57 (2002), pp. 113-156.

12 Durante el último cuarto de siglo XVIII, fruto de las constantes mejoras realizadas en el instrumento por diferentes constructores desde mediados de ese siglo, se consolidan dos tipos de pianos atendiendo al mecanismo interno que poseen: los de mecánica vienesa y los de mecánica inglesa.

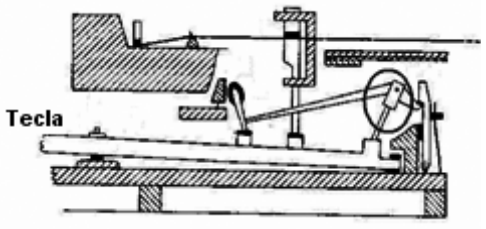

MECANISMO VIENES

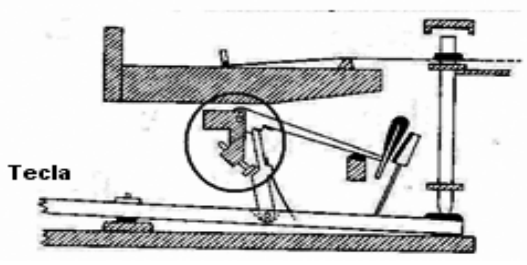

MECANISMO INGLES 
cuenta también en España en la actualidad con algunos instrumentos vieneses procedentes de la misma época ${ }^{13}$.

Encontramos un resumen de las características que presentaban dichos instrumentos en las primeras páginas de la versión española del texto didáctico de Muzio Clementi Introduction to the Art of playing on the pianoforte (Londres, Clementi/Banger/Hyde/Collard \& Davis, 1801), titulada Introducción al Arte de tocar el Piano-Forte en que se hallan los elementos de la Música, Ideas preliminares para la dirección de los dedos, Ejemplos, Preludios, muchas Lecciones con los dedos marcados y mucha variedad de Ayres nacionales de España y de otros países adaptados para el Piano-Forte. Dedicada a la Nación Española por el Autor, Muzio Clementi (Londres, Clementi/Banger/Hyde/ Collard \& Davis [Davison impr.], [1811]).

Allí se incluye, a modo de propaganda, el siguiente catálogo comercial, que resume las características que presentaban los pianos ingleses distribuidos por Clementi y Comp ${ }^{a}$ en España a principios del siglo XIX:

"Particularidades de los instrumentos de musica fabricados por Clementi y Comp ${ }^{\mathrm{a}}$. vendidores de musica de sus majestades y de la real familia, $n^{\circ} 26$, Cheapside, y á su fabrica real, TottenhamCourt Road en Londres:

Piano-Fortes Grandes. Piano-Fortes Grandes Verticales, mui hermosamente labrados y con las teclas adicionales hasta $\mathrm{C}$ en el baxo y hasta $\mathrm{F}$ en altisimo, á saber, seis diapasones y media. Idem de seis diapasones; Idem de cinco diapasones y media.

Piano-Fortes Grandes Horizontales de seis diapasones y media, mui hermosamente labrados y con los pies mui elegantes: Idem simples; Idem de seis diapasones; Idem de cinco diapasones y media.

Piano-Fortes Pequenos o Cuadrados. Piano-Fortes quadrados, simples, con teclas adicionales; Idem con dos gavetas; Idem, con tres gavetas; Idem mui elegantes. Piano-Fortes quadrados con teclas adicionales hasta $\mathrm{F}$ en altisimo; simples, 6 muí hermosamente labrados; Idem con teclas adicionales hasta $\mathrm{C}$ en el baxo y hasta $\mathrm{F}$ en altisimo, á saber, seis diapasones y media; Idem hermosisimamente labrados.

Piano-Celestino de patente Real. Este Piano de nueva invencion, es un instrumento hermosisimo en forma, y excelentisimo en son y facilidad de las teclas. Su mecanica es la mas simple y duradera possible; y las notas adicionales hasta $\mathrm{F}$ en altissimo son maravillosamente claras y brillantes. La estructura general de este instrumento lo riende admirable para quedar de acuerdo en todos los climas.

Organos de Celindro y para los dedos. HarPas con pedales. Instrumentos militares; y instrumentos musicales de todos los generos.

Los primeros producen un sonido mucho menos potente que los emitidos por un piano actual porque su mecanismo es mucho más frágil, dado que los macillos se hallan unidos al extremo interno de las teclas, debiendo, por tanto, situarse éstos en una posición más próxima a las cuerdas para poder percutirlas. Al reducir la distancia existente entre los macillos y las cuerdas, se provoca que éstos alcancen menos velocidad en su recorrido, mermando así también el volumen del sonido producido. La mecánica inglesa, más robusta y segura, pero también mucho más "dura" a la hora de tocar, separa los macillos de las teclas y los fija a una barra independiente, lo que le permite disponerlos en una posición más separada de las cuerdas que favorece una mayor potencia en la percusión.

13 Vid.: -Bordas Ibanez, Cristina: Instrumentos Musicales en Colecciones españolas. I. Museos de Titularidad estatal. Ministerio de Educación y Cultura. Madrid, Centro de Documentación de Música y Danza del INAEM, 1999, p. 181 (nº de referencia 345), donde figura información sobre una copia de un piano de cola vienés del siglo XVIII firmado por Dulcken. 
N. B. Todos los sobredichos instrumentos son fabricados de una estructura particularmente adaptada para las Indias Occidentales y Orientales.

Un Catalogo de composiciones musicales el mas grande en Europa”.

Tal y como se desprende del catálogo, la tipología de los pianos españoles usados durante aquella época respondía fundamentalmente a tres modelos: el piano de cola, que se utilizaba en audiciones públicas, pero también era el que poseía la clase social alta; el piano de mesa, que adoptaba una forma similar a la de un gran clavicordio y era utilizado en ambientes domésticos propios de la alta burguesía; y el piano vertical, de caja y tabla armónica mayor que la del de mesa, más decorativo, que poco a poco fue simplificando su aspecto e imponiéndose en el uso, ya a mediados del siglo XIX, al anteriormente descrito piano de mesa. Además, conviene resaltar que dentro de los modelos citados se daban ciertas variantes, que, como el Piano-Celestino de patente real mencionado en el catálogo anteriormente citado de "Clementi \& Comp".", sólo planteaban particularidades dentro de las tipologías generales antes mencionadas. Pero el piano más extendido en España hasta aproximadamente 1830 era el anteriormente citado piano de mesa, tipo inglés, que poseía una extensión de entre cinco octavas y media y seis, apagadores verticales, dos cuerdas por nota, generalmente un solo pedal -similar al pedal derecho actual, que levantaba todos los apagadores-y "mecanismo inglés doble"14.

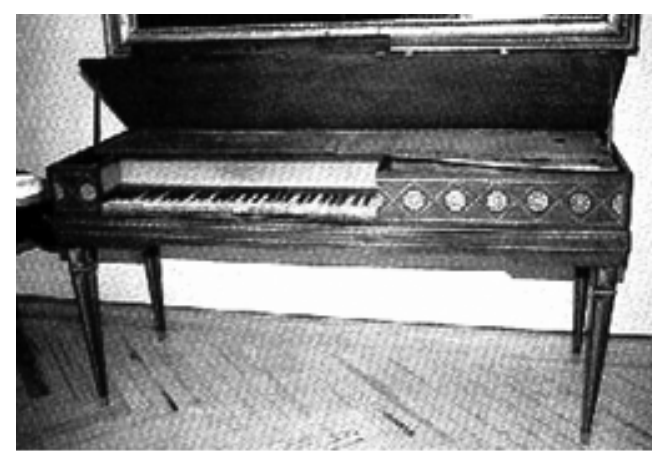

Piano de mesa Juan Hosseschrueders (1815?) Colección particular

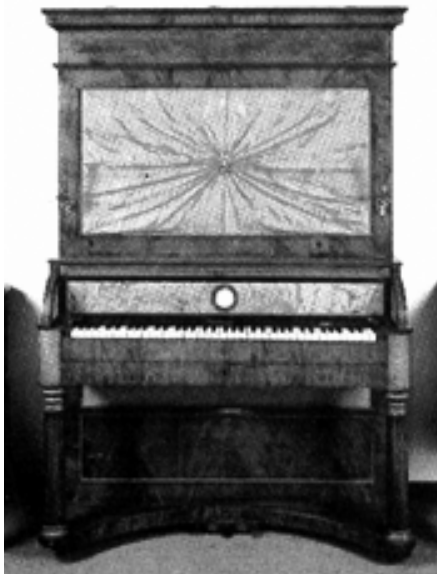

Piano vertical Hosseschrueders y sobrinos (1840c.) Colección HAZEN

14 Mejora realizada hacia 1786 por el constructor alemán emigrado a Londres Johann Geib (*1744; ${ }^{\dagger} 1818$ ), empleado de la firma Longman \& Broderip londinense, sobre el mecanismo simple inglés de J. Broadwood reproducido en la p. 5. Consistía en la interposición de una "doble palanca" entre el extremo posterior del macillo y el perno articulado a la tecla que al presionar ésta lanza el macillo contra la cuerda.

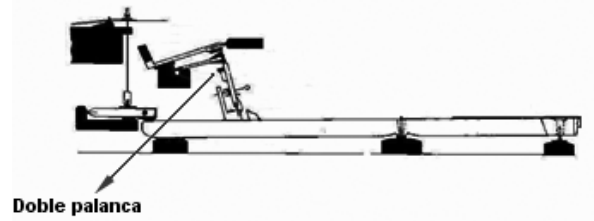

3 MECANISMO INGLES DOBLE (“ENGLISH DOUBLE ACTION") 
Pero el predominio del piano inglés fue debilitándose hacia 1830, cuando la manufactura autóctona comenzó a adecuar su fabricación al modelo francés, dado que la aplicación del mecanismo de repetición patentado en 1821 por Sébastien Érard $\left(* 1752 ;{ }^{\dagger} 1831\right)$, había impulsado/modernizado, en general, a toda la fábrica/industria francesa ${ }^{15}$.

El inicio de la construcción de pianos en Valencia se produjo, precisamente, hacia esta época. En la página 214 de la ya aludida Guía de naturales y forasteros en Valencia y su estado militar del año 1834 ya se anunciaba una "fábrica de pianos, chapas de caoba y azogar espejos, c. de S. Bartolomé, n. 2", dentro del apartado que englobaba las "Fábricas particulares de algunos artículos"; lamentablemente, no se da allí el nombre de su propietario ${ }^{16}$. Lo que sí se encuentra abundantemente documentado es que en 1830 fue fundada la fábrica de pianos valenciana de Pedro Gómez, considerada como la decana de la ciudad y una de las más importantes empresas locales del siglo XIX y principios del XX del sector ${ }^{17}$.

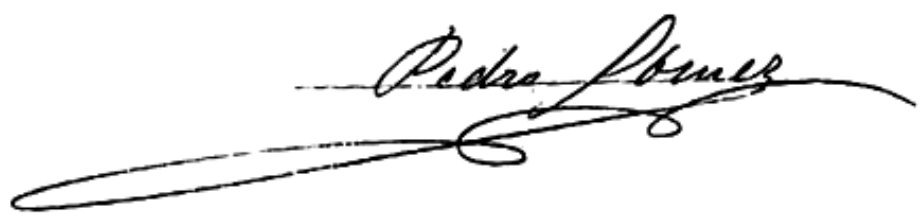

Firma de Pedro Gómez (hacia 1867)

$15 \mathrm{El}$ perfeccionado mecanismo inglés ( $v i d$. nota a pie precedente) comenzó a resultar obsoleto y fue reemplazado progresivamente por el "mecanismo de repetición" francés, que proporcionaba solidez, amplitud dinámica y exactitud al toque pianístico sin incrementar la "pesadez" del teclado.

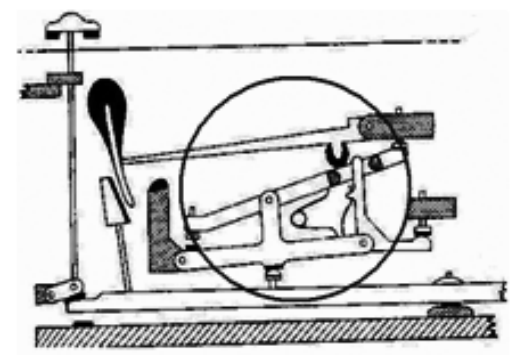

4 MECANISMO DE REPETICION PATENTADO POR ERARD. (PIANO MODERNO CON “DOBLE ESCAPE)

16 Cabría la posibilidad (?) de que el taller del maestro tornero o carpintero (pues también ofrecía en su publicidad "chapas de caoba y azogar espejos") que construía pianos por entonces en el $n^{\circ} 2$ de la calle de San Bartolomé de Valencia fuera el de Pedro Gómez, del que trataré a continuación, teniendo en cuenta la información con que se cuenta actualmente sobre dicha fábrica, y dada la coincidencia cronológica con el inicio de la actividad del mencionado constructor en la ciudad. Aunque la calle de San Bartolomé no se menciona como domicilio social del taller de Pedro Gómez en la documentación existente sobre la empresa después de 1875, podría ser que aquella hubiese sido su primera ubicación en la ciudad: Gómez é hijo (1867) se encontraba, primero, en la plaza de San Esteban (lugar donde aún se ubica el Conservatorio Profesional de la ciudad), 4, y cuando evolucionó en Manufactura de Pianos Gómez (1909c), amplió sus instalaciones y poseyó, además del citado domicilio de la plaza de San Esteban que por entonces aún conservaba, otro en "Almirante, P. G." (vid. reproducción de dicha propaganda en la p. 23).

17 Vid.: -Bordas Ibanez, Cristina: "Gómez, Pedro", en Diccionario de la Música Española e Hispanoamericana. Madrid, SGAE, 1999, vol. 5, p. 708. 
Pedro Gómez Peralta (*Teruel, 1812; †Valencia, 1887) ${ }^{18}$, antiguo aprendiz del taller barcelonés de órganos Font ${ }^{19}$, marchó a Madrid y entró a trabajar en el de los hermanos holandeses Juan y Pedro Hazen Hosseschrueders ${ }^{20}$, dónde se especializó en la construcción de pianos. De vuelta a Valencia en 1830, abrió taller propio, y se dedicó a la fabricación, primero de pianos "de mesa" y "de cola” y, tras un viaje a París (realizado, posiblemente, en la década de 1840) ${ }^{21}$ que le permitió ampliar sus conocimientos sobre las innovaciones practicadas allí al instrumento, comenzó a fabricar también "pianos derechos" (verticales).

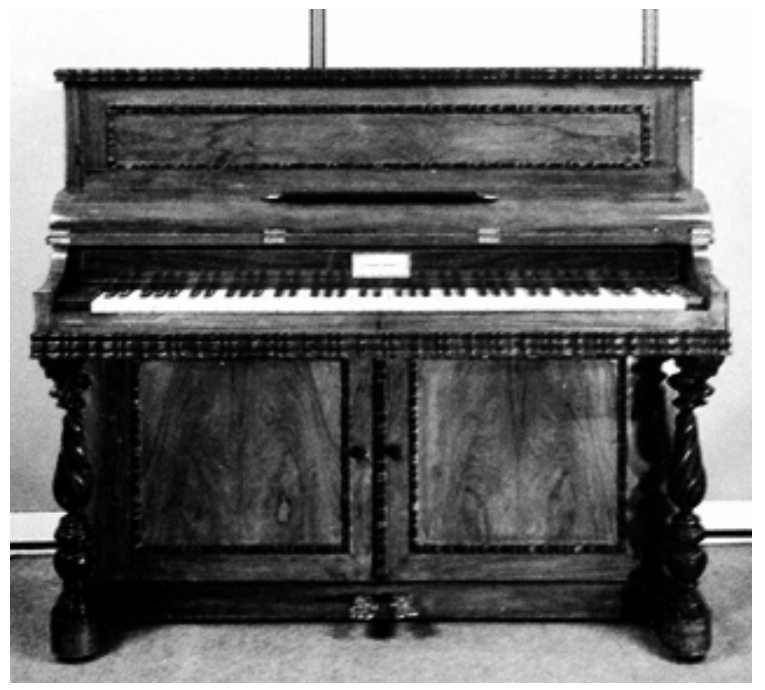

Colección Hazen: Piano vertical de Pedro Gómez (1860) que perteneció a José Iturbi22

Medalla de primera clase de la Sociedad Económica de Valencia en la exposición de 1851 por los pianos oblícuos

[verticales]

18 Los datos biográficos reseñados en cuerpo de página proceden de: -MAs, Manuel, dir. y prod.: "Gómez Peralta, Pedro", en Gran Enciclopedia de la Región Valenciana. Valencia, Graphic 3, 1973, vol. 5, p. 129. Se ha podido confirmar que la firma valenciana Gómez estuvo presente y obtuvo diversos galardones en exposiciones españolas y europeas (París 1878, 1889 y 1900), que refrendan la gran aceptación que obtuvieron sus instrumentos también fuera de nuestra ciudad (Vid.: -DelanNoY, Manuelle: "La facture instrumentale espagnole aux expositions universelles parisiennes de 1855 a 1900", en Nassarre X/2 (1994), pp. 9-16; donde se cita la participación de Gómez e hijos sin detallar correctamente la procedencia regional española de la firma, pues se señala erróneamente como barcelonesa). No se ha recabado documentación alguna, sin embargo, de los premios conseguidos en América que, según señala la biografía utilizada (mencionada al principio de esta nota), Pedro Gómez también consiguió en certámenes americanos. Cfr. también: -Bordas Ibanez, Cristina: "Gómez, Pedro”, en Diccionario de la Música Valenciana. Madrid, Iberautor, 2006, vol.1, p. 451.

19 Según documentación procedente del antiguo Instituto Español de Musicología (en la actualidad Departamento de Musicología del Consejo Superior de Investigaciones Científicas -CSIC en Barcelona-), el taller organero de la familia Font trabajó en la ciudad condal a lo largo de todo el siglo XIX. Dicho fondo aporta datos concretos sobre Juan Font, maestro organero barcelonés que construyó el órgano de San Juan de las Abadesas en 1818 (-Gudiola i CuniLl, Josep: Nocions de arqueología sagrada catalana. Vich, Imprenta de la viuda de R. Anglada, 1902, vol. 2, p. 696) y de Esteban Font, discípulo de Puig (Juan Puig se estableció en Barcelona a mediados del siglo XIX después de haber permanecido muchos años en el extranjero; autor, entre otros, del órgano de San Jaime Apóstol de Barcelona y también restaurador del de Santa Clara. Vid.: -PEDRELL SABATE, Felipe: Documentos inéditos para su Diccionario. Biblioteca de Cataluña, signatura M. 942). El citado Esteban Font fue el encargado de restaurar el órgano de San Pablo del Campo, inaugurado públicamente en 1864 (Diario de Barcelona, 24/III/1863; y Almanaque del Diario de Barcelona, 1864, p. 123).

20 Juan y Pedro Hazen Hosseschrueders eran sobrinos de Jan Hosseschrueders constructor de pianos que abrió una fábricataller en Madrid en 1814 (ya citado en p. 4). Desde 1830 aproximadamente, el taller estuvo en manos de dichos hermanos porque su tío, entonces conocido por el castellanizado nombre de Juan, regresó a su lugar de origen, los Países Bajos. Vid.: -BoRDAS IBANEZ, Cristina: Hazen y el piano en España, 175 años. Madrid, Hazen, 1989, p. 30; e -ID: "Hazen", en Diccionario de la Música Española e Hispanoamericana. Madrid, SGAE, 2000, vol. 6, p. 220.

21 Como se detallará a continuación, posiblemente inmediatamente después de haber realizado Pedro Gómez su viaje a París (y dando muestra del provecho que le había sacado), los pianos construidos por el fabricante ganaron la Medalla de primera clase en la Exposición valenciana de 1851convocada por la Real Sociedad Económica de Amigos del País local.

22 Fotografía reproducida de: -Bordas IBANEZ, Cristina: Hazen y el piano en España...op. cit., p. 97. 
De acuerdo con esos datos, probablemente Pedro Gómez comenzara siguiendo el modelo inglés hacia 1830, ya "anticuado" para los constructores establecidos en otras ciudades españolas, y adoptara el francés más tardíamente, hacia 1850, después de volver de su viaje a Francia. Lo cierto es que, según consta en el Archivo Documental de la Real Sociedad Económica de Amigos del País en Valencia, esta empresa ya obtuvo la Medalla de primera clase en la Exposición valenciana de 1851, celebrada por la Económica valenciana, por sus pianos verticales.

A pesar de su avanzada especialización en la construcción de pianos ya hacia 1840, Pedro Gómez construía también entonces órganos y armonios, y lo mismo sucedía con la mayoría de "pianistas" españoles (también denominados "pianeros") de aquella época ${ }^{23}$. Aparte de ajustarse así a una ambigüedad entonces normal en relación con el uso de instrumentos de teclado, se respondía a una tradición gremial española que fomentaba que los instrumentos de teclado se construyeran en talleres de organería $^{24}$ que, a su vez, debían encontrarse suscritos, como todos los que se dedicaban a fabricar instrumentos musicales, al gremio general de torneros (carpinteros o ebanistas) ${ }^{25}$.

Pedro Gómez concurrió, asimismo, a la Exposición Regional de 1867, nuevamente convocada por la Económica valenciana. Su hoja de inscripción, reproducida en las páginas siguientes, refiere que aportó en aquella ocasión cinco pianos verticales oblicuos (disposición cruzada de las cuerdas) provistos de mecanismo de repetición ${ }^{26}$ y dos registros (pedales): el de resonancia y el denominado "una corda".

23 Muchos talleres continuaron construyendo en Valencia otros instrumentos de teclado además del piano en fechas bastante posteriores, como veremos más adelante. Esta circunstancia también se dio en empresas procedentes de otras regiones españolas, como por ejemplo la del granadino Adolfo Montero Weiss. Vid.: -GARCIA Mallo, M. Carmen: "Peters y España: edición musical y relaciones comerciales entre 1868 y 1892”, en Anuario Musical, 60 (2005), pp. 115-167.

24 Aunque la práctica extinción legal de los gremios se produjo ya en las primeras reuniones de las Cortes de Cádiz de 1808, los talleres españoles ya especializados en la construcción de pianos siguieron produciendo órganos y armonios.

25 Vid. -Borras Roca, Josep y EzQuerro Esteban, Antonio: "Chirimías en Calatayud. Principio y final de un proceso constructivo" en Revista de Musicología, XXII/2 (1999), pp. 66-74.

26 El mecanismo de repetición del piano de cola, que es lo que aligera el funcionamiento del instrumento, se fundamenta en que las nuevas percusiones sucesivas de un mismo sonido se realicen desde una distancia intermedia entre el punto de reposo del macillo y la cuerda. Así, cuando una tecla es bajada, el mecanismo responde lanzando el macillo contra las cuerdas para realizar la percusión, pero al caer, si la tecla continúa presionada, el macillo, que cae por su propio peso obedeciendo a las leyes de la gravedad, es atrapado hacia la mitad del recorrido que existe entre su posición de reposo y las cuerdas . La nueva percusión se realizaría sólo levantando un poco el dedo de la tecla, sin que hubiese necesidad de atacar desde arriba habiéndola soltado previamente. El piano vertical no tiene mecanismo de repetición propiamente dicho, ya que toda su mecánica está "levantada", y el macillo no vuelve a su posición de reposo (o es atrapado) por su caída natural, aprovechando la gravedad, lo hace gracias a unos muelles que lo arrastran una vez soltada la tecla. Por tanto, su teclado, que intencionadamente tiene menor recorrido para sugerir mayor ligereza (aunque en casos particulares se prefiera ampliar el calado que resultaría conveniente, y se dé pesantez a las teclas para que se "asemejen" al teclado de un piano de cola), suele mostrarse menos exacto cuando es "golpeado" desde arriba en pasajes veloces o que exigen repetición sucesiva de las mismas notas

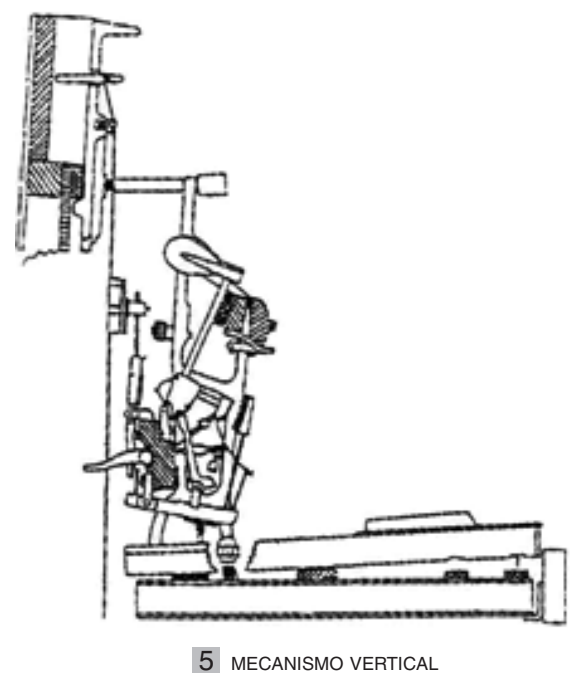




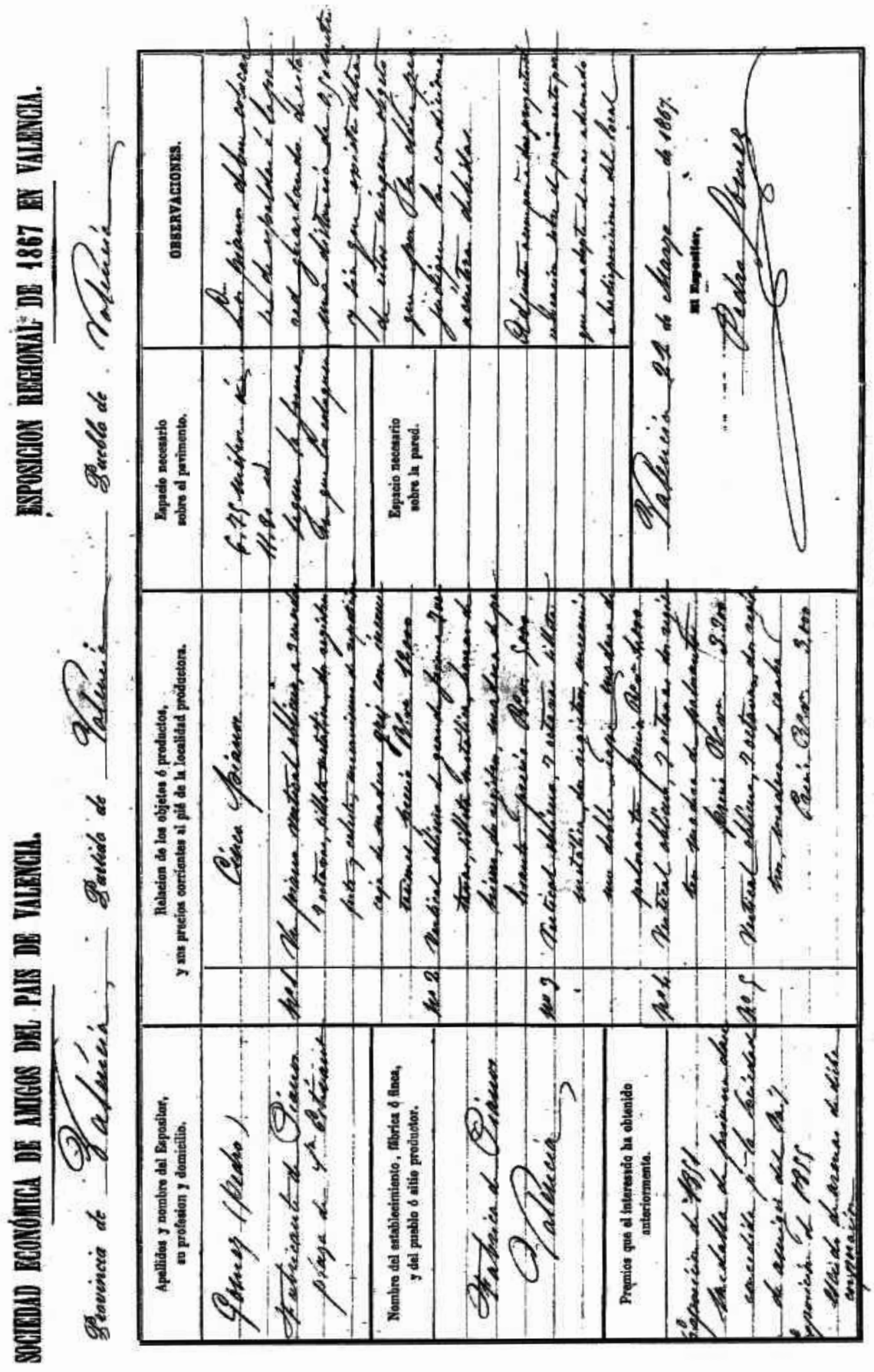

Hoja de Inscripción de Pedro Gómez en la Exposición Regional de 1867

(Archivo de la Real Sociedad Económica de Amigos del País de Valencia, signatura R.S.E.A.P.V., 1867, C-174, IX Exposición Regional, nº 11. Relación de expositores) 


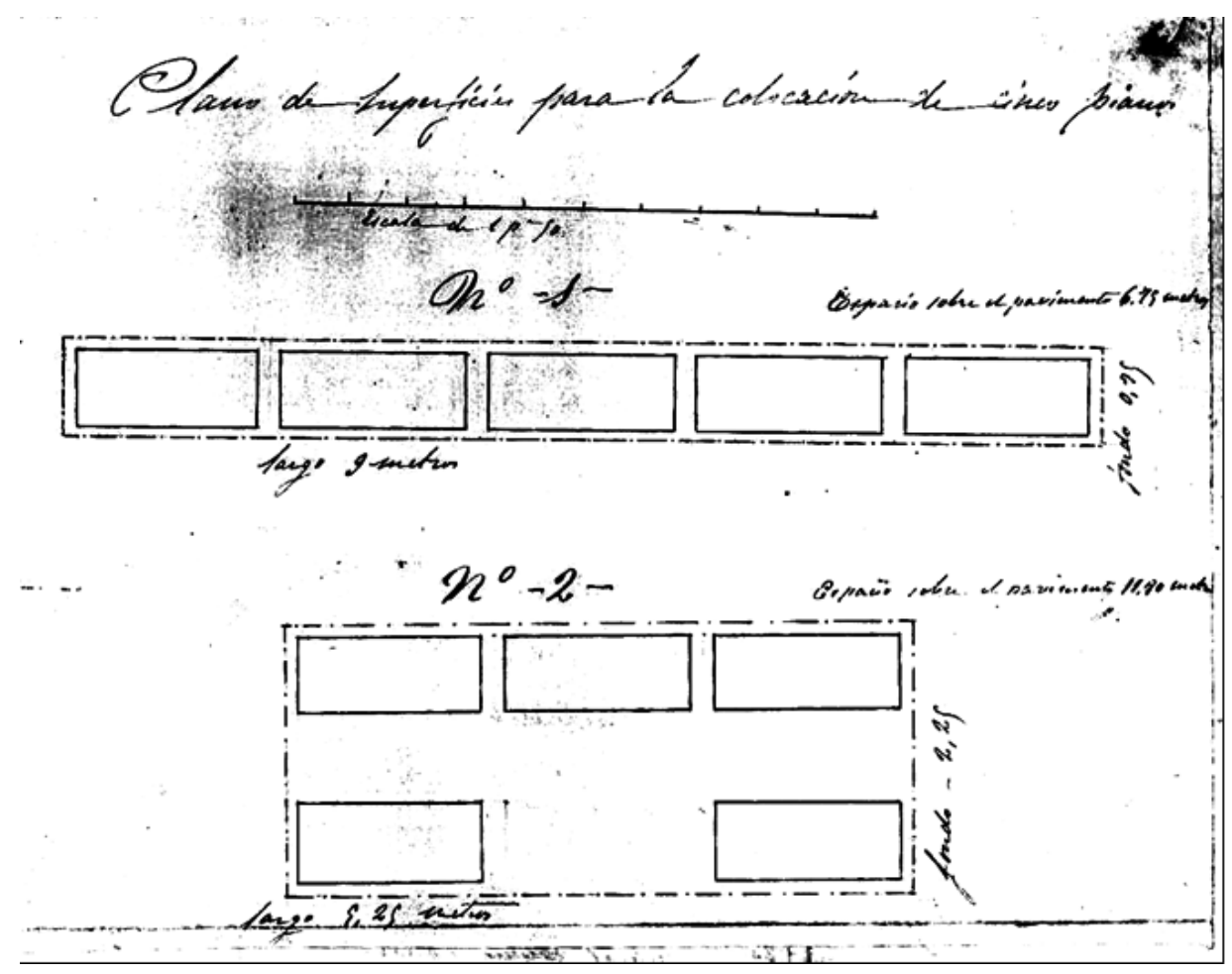

Propuesta de colocación de los cinco pianos aportados por Pedro Gómez en la Exposición Regional de 1867 adjuntada a su Hoja de Inscripción.

Como puede observarse en la ficha de inscripción precedente, el precio de los pianos expuestos entonces por la firma Pedro Gómez (12.000, 5.000, 4.000, 3.300 y 3.000 reales), dependía de algunas de sus prestaciones mecánicas -los dos más caros poseían silleta metálica y barraje de hierro-, y de la calidad de las maderas utilizadas para confeccionar sus muebles -el inferior lo posee de madera de caoba, tres de ellos son de palosanto y el superior "de madera gris con incrustaciones"-. Con ello se pretendía surtir una demanda local de instrumentos encaminada hacia clases sociales intermedias que requerían instrumentos más económicos y, por tanto, menos lujosos.

Entre el resto de documentos que describen los productos que concurrieron a la Exposición Regional de 1867 no se encuentra ninguno que acredite la participación de otro taller que se dedicara por entonces en Valencia a la construcción de $\operatorname{pianos}^{27}$.

27 Entre las hojas de inscripción a la Exposición Regional de 1867 consultadas en el archivo de la Real Sociedad Económica de Amigos del País en Valencia, constan las aportaciones realizadas por José Bellver y Vila -profesor de música que podría estar emparentado con el pianista y profesor de piano del Conservatorio de Música de Valencia José Bellver Abells (*1869; $\left.{ }^{\dagger} 1945\right)-$ y Vicente Ramón, que expusieron 2 órganos-armonios y un armonio de transposición con 3 registros y 5 octavas, respectivamente. Esto demuestra que otros talleres, aparte del de Pedro Gómez, se dedicaban hacia 1867 en Valencia a la construcción de instrumentos con teclado y, dado que eran este tipo de factorías las que se encargaban también de la construcción de pianos, podría haber ocurrido que dichos constructores fueran los antecesores de otras fábricas de pianos aparecidas en la ciudad alrededor de 1880. 
Ya próximos al último cuarto de ese siglo, la fabricación española imitó, en general, la construcción de pianos alemana y norteamericana, basada ya en los nuevos sistemas de fabricación, más modernos y productivos. El siguiente paso se daría a principios del siglo XX, cuando los talleres españoles, desbordados ante la demanda de instrumentos requerida por la sociedad de la época, limitaron su cometido, y comenzaron a importar los mecanismos de los pianos ya manufacturados, o comprados por elementos, para instalarlos/montarlos en muebles de diferentes calidades, confeccionados, éstos sí, por ellos mismos.

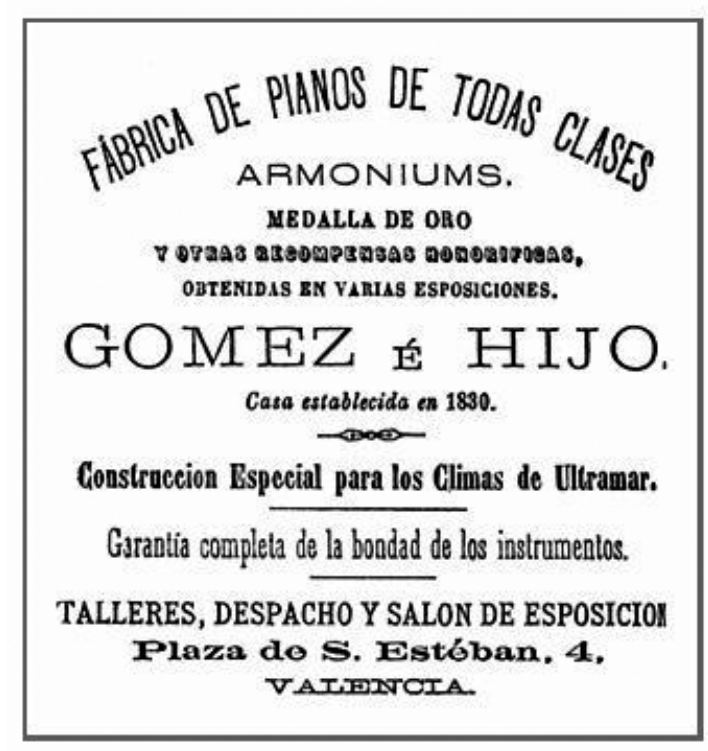

Publicidad que difunde Gómez é Hijo hacia 1877.

Asimismo, cabría destacar que dicha demanda de pianos provocó también un incremento de la exportación de los instrumentos manufacturados en la península hacia las provincias españolas insulares (Baleares y Canarias) y, sobre todo, a las colonias. Por ello es común, entre la propaganda comercial de las fábricas españolas de pianos de aquella época, especificaciones como la que incluye el anuncio que Gómez é hijo insertó en la prensa valenciana hacia 1877 (imagen precedente 28 ): "Construcción Especial para los Climas de Ultramar”. Con ello se hacía constar la calidad de las materias primas que se empleaban en su construcción, pues los pianos debían, primero, soportar un largo viaje vía marítima, y, después, aclimatarse bien a la temperatura, humedad extrema y otros agentes externos de las regiones hacia las que se dirigían. Esta preocupación comercial había sido y sería constante para los fabricantes de pianos en todas las épocas (vid. propaganda de los pianos "Clementi y Comp" hacia 1811).

28 Imagen reproducida del Itinerario nomenclator de las calles y plazas de Valencia y reseña de sus principales edificios. Valencia, Pascual Aguilar, 1877, s. p. [anuncios sin paginar]. 


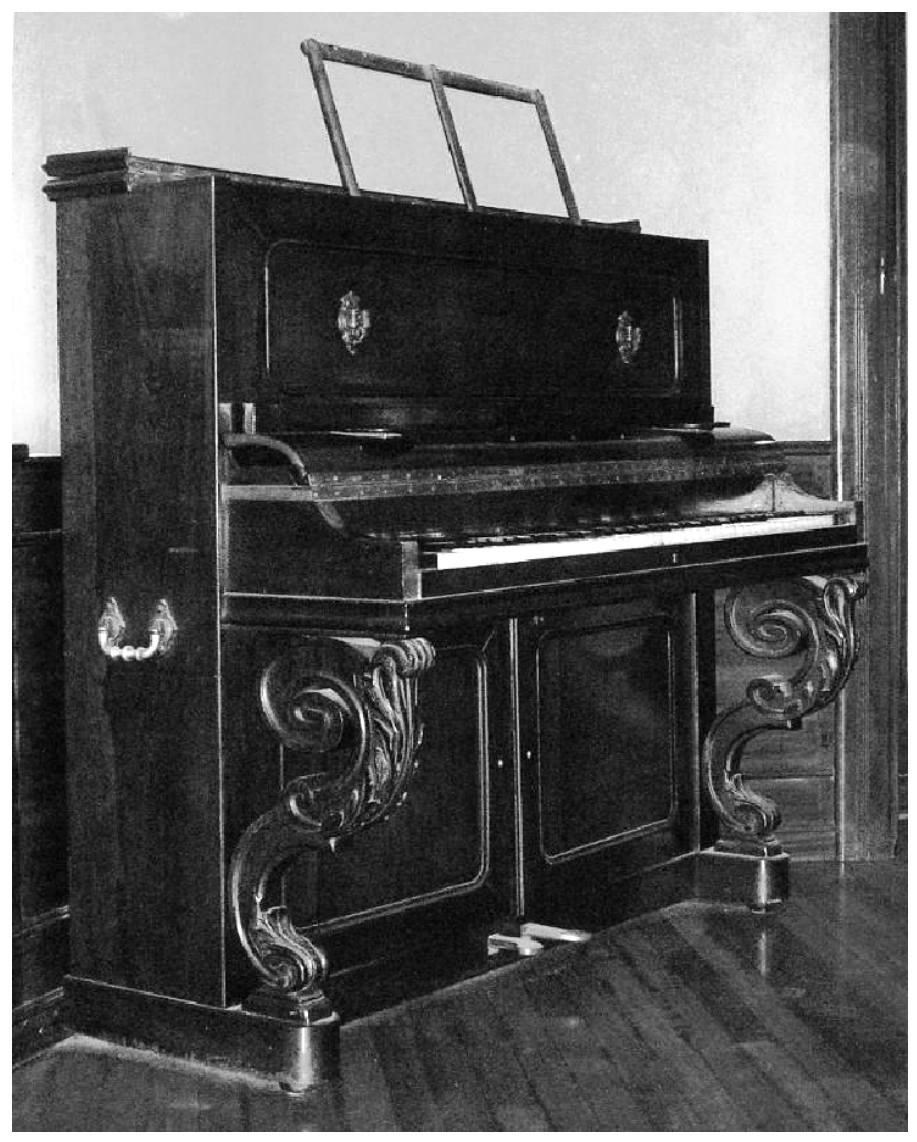

Piano vertical Gómez é Hijo (1870c)

Valencia. Sociedad Valenciana de Agricultura.

Pedro Gómez, sin embargo, no fue la única fábrica de construcción de pianos -e instrumentos con teclado- que existió en la capital levantina durante la segunda mitad del siglo XIX. El Catálogo General de la Exposición Regional de Agricultura, Industria y Artes (1883) publicado por la Sociedad Económica de Amigos del País valenciana, menciona, dentro del apartado que relaciona las empresas expositoras de la "Clase 48" -Imprenta y librería. Encuadernaciones. Material de la pintura y el dibujo. Modelos. Instrumentos de música. Pruebas y aparatos de fotografía. Material y procedimientos de telegrafía- dos que expusieron pianos en aquella ocasión además de Gómez é hijo (antes Pedro Gómez): Galiana (D. José), que muestra seis pianos, y Carreres (D. Mariano), que contribuye con dos, y resultará finalmente premiado. Ese Catálogo General no aporta, desgraciadamente, ninguna descripción que ayude a conocer las prestaciones o la conformación que caracterizaban a los instrumentos fabricados por esas dos casas valencianas. 

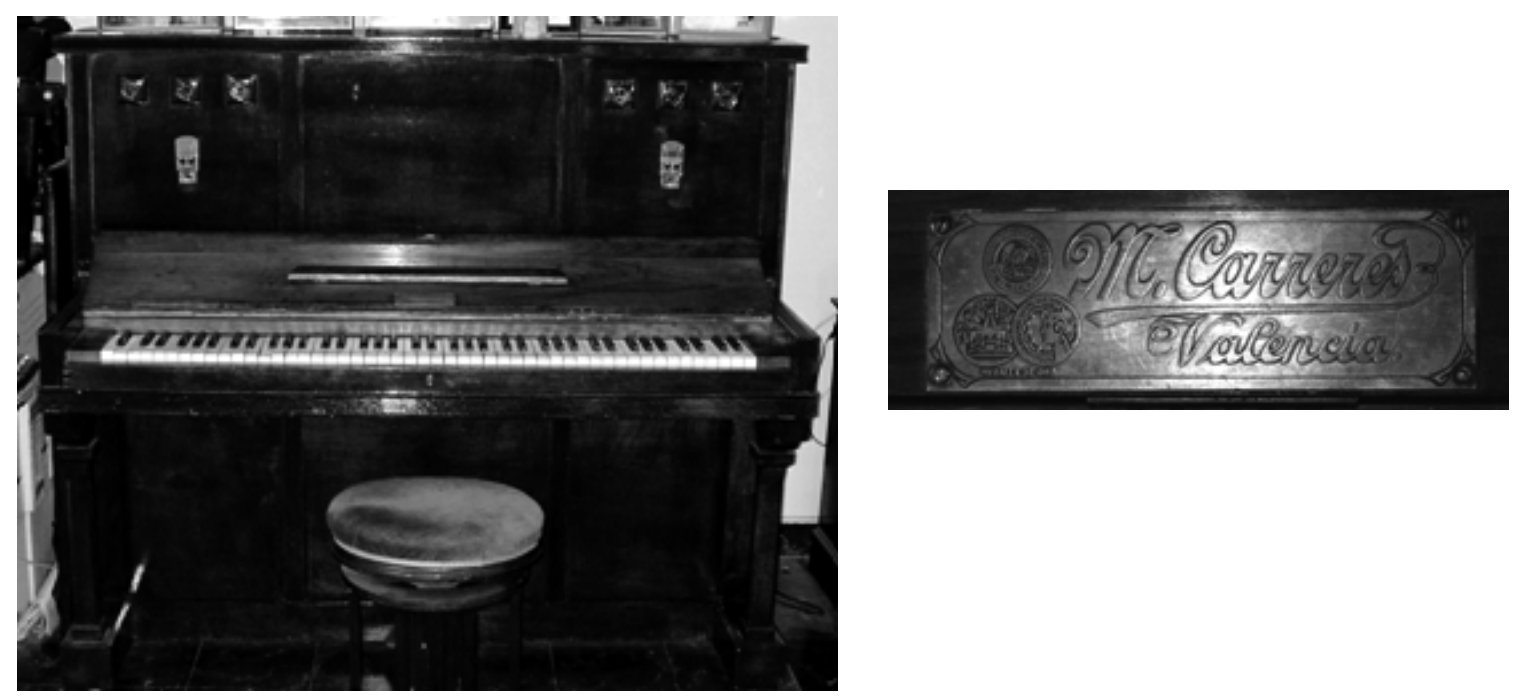

Piano vertical de Mariano Carreres (s. XX) que perteneció al pianista Ramón Martínez Carrasco 29

Las medallas que aparecen en la placa distintiva reflejan los galardones obtenidos: la primera le fue otorgada por la Real Sociedad Económica de Amigos del País (no se aprecia la fecha); las dos de abajo son el anverso y el reverso de la "de oro" conseguida en la Exposición Regional Valenciana de 1909.

Piano vertical Galiana hijo (s. XX)

Valencia, Museo Nacional de Cerámica y

Artes Suntuarias “González Martí”30.

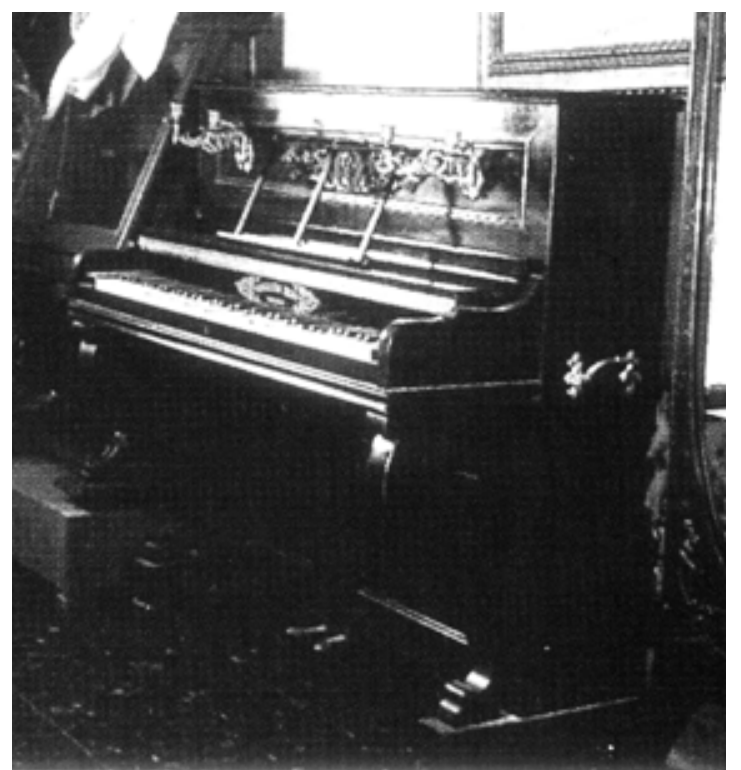

29 Actualmente este piano pertenece a Ramón Martínez Quinzá -hijo y heredero del pianista Ramón Martínez Carrasco, profesor y director del Conservatorio de Valencia en dos períodos (1910-1920 y 1933-1935)-, quien me explicó que su padre lo compró tras verse obligado a vender su piano de cola Bechstein.

30 -Bordas Ibanez, Cristina: Instrumentos Musicales en Colecciones Españolas. Vol. 1. Museos de titularidad Estatal. Ministerio de Educación y Cultura. Madrid, Centro de Documentación de Música y danza (INAEM), 1999, p. 195. 
Gómez é hijo había contribuido a la Exposición de 1883 con abundante material relacionado con el piano, el cual aparece detallado con mucha más minuciosidad que la mercancía expuesta por Galiana o Carreres en el Cátalogo General de dicha muestra:

«Siete pianos de diferentes modelos [¿de cola y de mesa/verticales?]: banquetas, accesorios de aisladores, etc.»

La sutil diferencia que presenta la forma de enumerar estos artículos en dicho catálogo pone en evidencia el estatus de privilegio que, probablemente, mantenía en la ciudad la fábrica de Pedro Gómez durante aquellos años ${ }^{31}$, aunque el "trato de favor" también podría deberse a que la cantidad de pianos y accesorios aportados por Gómez é hijos a dicha Exposición fuera bastante superior a los mostrados por Galiana o Carreres.

Ese mismo catálogo general de la Exposición Regional Valenciana de 1883 recoge, además, la participación de tres fábricas de pianos barcelonesas junto a los mencionados constructores valencianos: Bernareggi, Gassó y $C^{a}$ (después de 1890 denominada Bernareggi, Estela y $C^{a}$ ), Nogués Moliner y Soler, y Raynard y Maseras ${ }^{32}$.

Las firmas catalanas participaron, mostrando el auge que había cobrado por entonces en Barcelona este tipo de manufacturas, con los siguientes instrumentos:

- Bernareggi, Gassó y $C^{a}$ : un piano gran cola para concierto, un id. vertical de gran forma, un id. medio oblicuo [con cuerdas cruzadas], un id. cuarto oblicuo y un piano vertical: un armonium de concierto [?]. - Nogués Moliner y Soler: un piano grande oblicuo y otro piano medio oblicuo.

- Raynard y Maseras: un piano oblicuo de gran forma, otro id. vertical, un armonium, órgano extra y otro id. [armonium].

Además de los datos relacionados, dicho catálogo general incluye importante información complementaria acerca de las mencionadas fábricas. Nogués Moliner y Soler (antes Lerch) ${ }^{33}$ establecida en Barcelona hacia 1843, contaba ya en 1883 con 30 operarios y su facturación anual era aproximadamente de 100 pianos, que se exportaban a "España y Ultramar". Respecto de Raynard y Maseras, detalla que, habiendo sido fundada en 1871, en 1883 contaba con 40 operarios, y su producción anual entonces era de 300 pianos anuales que también distribuía a la "Península y Ultramar". La propaganda de esta última en el catálogo que se maneja subraya también que el sistema de "equilibración [de sus instrumentos] es especial y da satisfactorios resultados sin resentirse á las variaciones del clima",

31 Vid.: -Sociedad Económica de Amigos del País en Valencia: Exposición Regional de Agricultura, Industria y Artes. Año 1883. Catálogo general. Valencia, Imprenta Casa de la Beneficencia, 1883, p. 176.

32 Vid.: -Bordas, CRISTINA: "Piano. IV. Siglos XIX y XX", en Diccionario de la música Española e hispanoamericana. Madrid, SGAE, 2000, vol. 8, p. 761, donde se ofrecen datos sobre los constructores barceloneses citados y de otros que trabajaron en el resto de España durante esos siglos. Además, el artículo de: -Borras RocA, Josep y EzQuERro EsteBAn, Antonio: "Chirimías en Calatayud. Principio y final de un proceso constructivo", en Revista de Musicología, XXII/2 (1999), pp. 66-74, que documenta sobre el asentamiento de constructores de instrumentos extranjeros en Barcelona desde finales del siglo XVIII (principalmente franceses e italianos), recoge datos sobre el examen realizado para ingresar en el "Gremi de Torners" de dicha ciudad (condición imprescindible para abrir allí taller entonces) de dos antecesores de los fabricantes de piano arriba mencionados: Louis Boisselot (*1754), que lo efectuó en 1799, y Francisco Bernareggi, que lo superó más tarde, en 1819.

33 La empresa Lerch, de procedencia suiza, se estableció en Barcelona durante la segunda mitad del siglo XIX, sucediendo, al parecer, a una firma anterior, Camps. Lerch cambiará hacia 1883 su nombre por el de Nogués Moliner y Soler, empresa que participó en la Exposición Valenciana de 1883. Vid. -Bordas IBAnEZ, Cristina: "Piano. IV. Siglos XIX...”, op. cit., vol. 8, p. 761. 
lo que significa que durante su confección, lo mismo que Clementi y Comp ${ }^{a}$. a principios del siglo XIX y el valenciano Gómez é hijo hacia 1877, Raynard y Maseras, en un afán exportador y con gran visión comercial, tenía en cuenta las posibles condiciones climáticas "más extremas" tanto de nuestro país, como de las colonias españolas norteafricanas, americanas y asiáticas (Filipinas).

La presencia de estas marcas catalanas en una Exposición Regional Valenciana podría indicar que dichas empresas ya colaboraban entonces con algún comercio valenciano de distribución de instrumentos $^{34}$, o que, en caso de que todavía no lo hicieran, desearan abrirse camino después de 1883 en el mercado musical local (este hecho se dio también en otros ámbitos, como por ejemplo el de la edición musical, cuando Ildefonso Alier, empresa editora catalana con sede en Barcelona, expansionó su negocio alrededor de 1911 hacia otras zonas como Madrid o Valencia, estableciendo en estas ciudades sedes dependientes de la central barcelonesa). Es curioso comprobar que, en los tres casos, los instrumentos aportados por cada una de estas empresas catalanas son descritos con mayor minuciosidad que los expuestos por los talleres valencianos, prueba del prestigio que poseían estas fábricas ya hacia finales del siglo XIX en el ámbito comercial nacional.

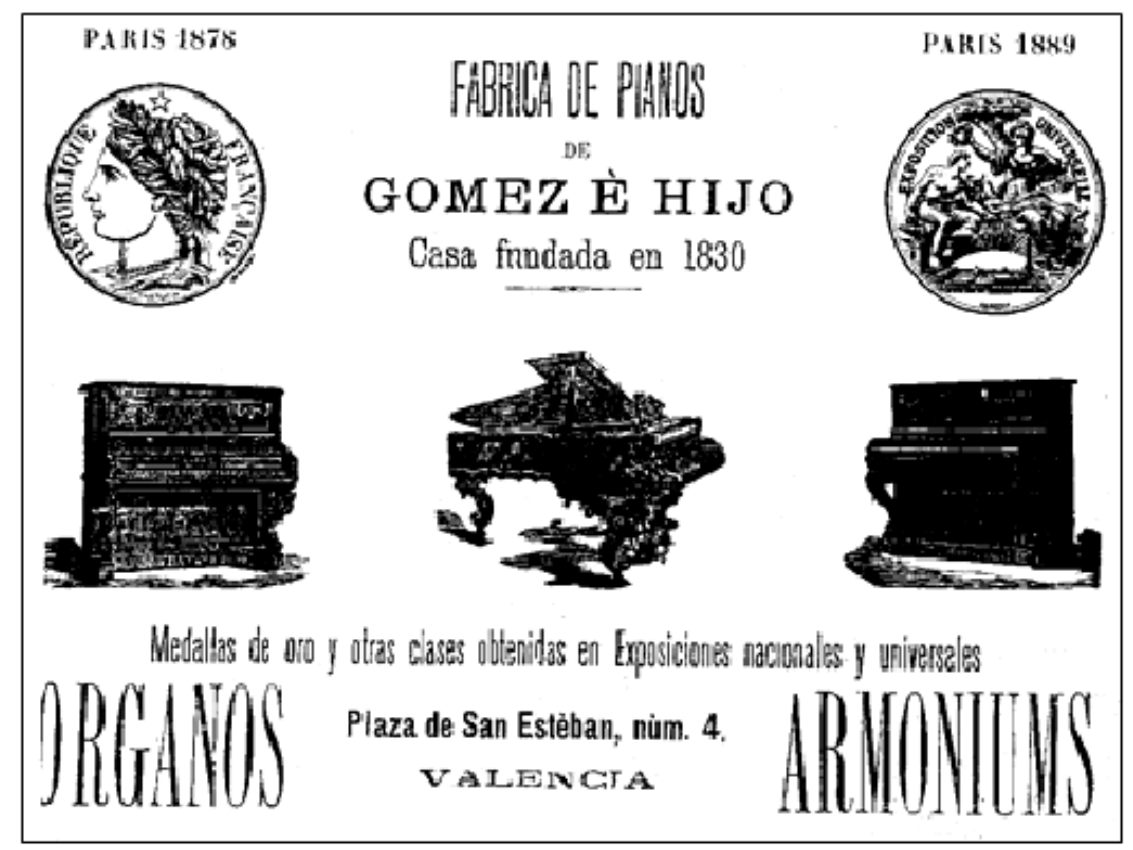

Anuncio de la empresa Gómez è hijo (antes Pedro Gómez) hacia 1893

34 En la página 30 se reproduce un anuncio en el que se especifica que el comercio musical valenciano Casa Turell fue el único que poseyó durante la década de 1890 en Valencia el depósito y la representación de los pianos Bernareggi, Estela y C ${ }^{a}$, empresa de ascendencia italiana sucesora de la que se publicitó y mostró sus instrumentos en la Exposición Regional Valenciana de 1883. Pero, además, casa Turell ofertaba también pianos de otras firmas barcelonesas como Boisselot o Chassaigne (esta vez de ascendencia francesa). 
Como queda dicho, la fábrica de Gómez e hijo estuvo ubicada, al menos desde el año 1867, en el número 4 de la Plaza de San Esteban, localización estratégica por su proximidad con la que el Conservatorio de la ciudad tuvo a partir de 1881. A juzgar por los galardones que recibió en las Exposiciones de París de los años 1878, 1889 y 1900, por los premios nacionales (en la Exposición Regional de Valencia de 1909, que se prolongó como Exposición Nacional, durante 1910) y los obtenidos en muestras universales (¿por su participación en la Exposición Universal de Barcelona de 1888 además de la de París que ya se hacía constar en su propaganda?), parece que sus instrumentos ya habían alcanzado un apreciable grado de calidad hacia principios del siglo XX.

Además, según reseñas periodísticas publicadas hacia finales de ese siglo, Gómez e hijo poseía una sala (donde se celebraban audiciones públicas y recitales de piano) similar a las que tenían otros comerciantes relacionados con el ejercicio musical. Una de las más célebres fue el "Salón Romero", propiedad del clarinetista, editor y almacenista madrileño Antonio Romero y Andía, que sirvió de escenario a tantos y tan importantes estrenos musicales. En un ámbito más local, conviene citar el Salón Sánchez Ferrís, que tuvo en Valencia el editor y comerciante musical Antonio Sánchez Ferrís por la misma época.

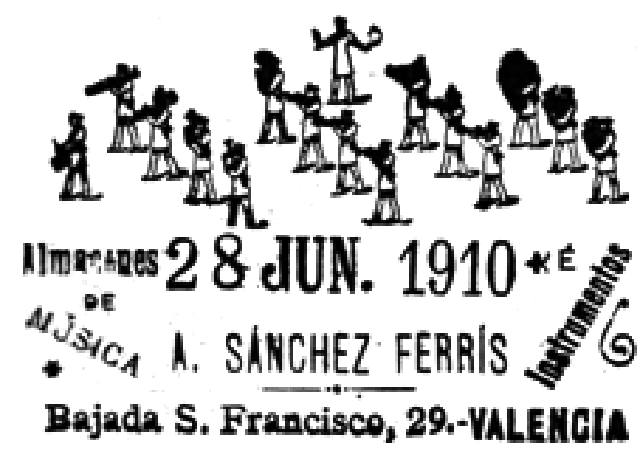

Sello del comercio de Antonio Sánchez Ferrís (1910)

En los años entre siglos (1890-1910) fue cuando, al parecer, Gómez è hijo-que alrededor de 1909 pasaría a denominarse Manufactura de pianos Gómez- alcanzó cierto renombre en el mercado nacional. Sus pianos aparecían ofertados por entonces en el ya importante establecimiento Hazen de Madrid $^{35}$ junto a los de otras marcas españolas -principalmente barcelonesas- como Chassaigne Frères, Maristany, Priu Mallard o Ricardo Rodríguez. Además, consta en el archivo de la citada empresa Hazen, que Gómez e hijo fueron proveedores de la Real Casa en 1908, honor que se sumaba al éxito comercial alcanzado por este establecimiento valenciano a principios del siglo XX.

Pero, ese auge experimentado por la firma valenciana Gómez e hijo a principios del siglo XX fue común para toda la industria "pianística" regional española, pues había resultado impulsada en los últi-

35 Vid. -Bordas Ibanez, Cristina: “Los pianos Hosseschrueders y Hazen”, en Hazen y el piano en España, 175 años. Madrid, Hazen, 1989, p. 67. 
mos años del siglo XIX en general por efecto de dos hechos fundamentales: la Exposición Universal de Barcelona en 1888 y la aplicación en 1893 de la reforma arancelaria. Si la contribución de la citada normativa arancelaria fue decisiva al plantear las medidas que protegerían en adelante el producto nacional, y fijarían la normativa que regiría las condiciones de instalación en nuestro país de marcas extranjeras, la influencia de la Exposición Universal de Barcelona de 1888 no fue menor, pues daría a conocer en España sistemas de producción más modernos y nuevas técnicas en cuanto a la construcción de instrumentos que pronto serían implantadas por las factorías españolas. El artículo "La fabricación española de pianos”, aparecido en el Boletín Musical de Valencia n 225 (10.05.1900), p. 1717, que daba un marco histórico a la industria pianística nacional de principios de siglo, describe así la trascendencia que tuvo para los "pianistas" españoles aquella Exposición barcelonesa:

«Poco después de la memorable Exposición Universal de Barcelona de 1888, algunos fabricantes de pianos comprendieron que se hacía indispensable modernizar su fabricación, pues de lo contrario estaban destinados a desaparecer. Unos con desgracia, otros con mediano éxito aplicaron el marco de hierro al piano, dejando de lado la escuela francesa, a pesar de que sus directores lo eran [Boisselot, Chassaigne, etc.], para copiar ciertas marcas alemanas que al fin y al cabo habian copiado á su vez el sistema de construcción norte-americano, é importando todo el material del extranjero...».

Pero las novedosas condiciones que presentaban las fábricas de pianos españolas en los primeros años del siglo XX se encuentran también detalladas en la prensa musical valenciana de la época. Concretamente, un Boletín Musical de Valencia anterior, el no 202 (20.09.1899), ya dedicaba sus páginas 1557-1558 a la fábrica de pianos Ortiz \& Cussó de Barcelona, pujante hacia principios de siglo. Allí se pone en evidencia, por una parte, la expansión comercial que alcanzó la mencionada empresa barcelonesa en el mercado nacional de su época y, por otra, el interés de los comercios valencianos por adquirir la distribución exclusiva en su zona. Conviene tener en consideración que el editor y propietario de la citada revista, el ya citado Antonio Sánchez Ferrís, también dueño del antiguo comercio y editorial musical valencianos Casa Laviña (firma que se había hecho por entonces con la concesión de la distribución en exclusiva de pianos de la citada marca en Castellón, Valencia y Alicante), se hacía publicidad con el mencionado artículo.

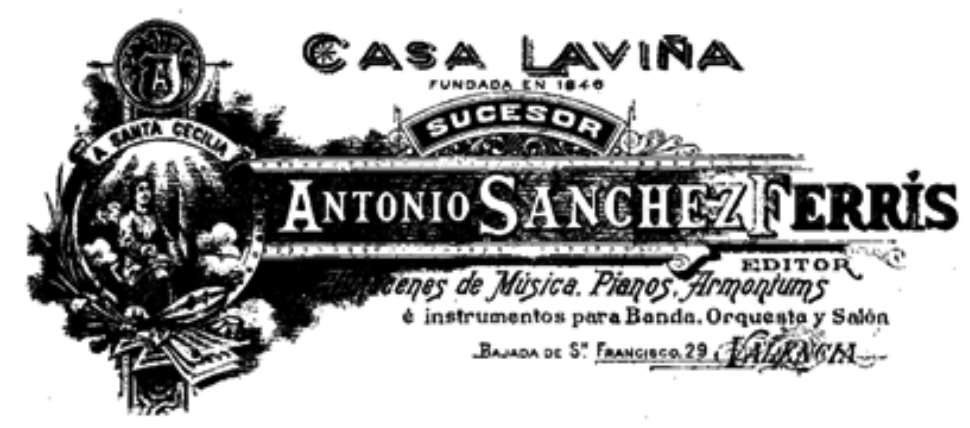

Logotipo usado por el editor Antonio Sánchez Ferrís en 1899

Boletín Musical de Valencia n $^{\circ} 202$ (1899) 
No obstante, dejando a un lado lo que es claramente pura propaganda, el texto ofrece datos importantes sobre dicha firma. En él se describen ampliamente las instalaciones con que contaba Ortiz \& Cussó en la Barcelona de 1899: ubicada en la calle Ramalleras n 19 , dentro del casco antiguo y centro de la ciudad, ocupaba, en su totalidad, un edificio integrado por planta baja y cuatro pisos que poseían fuerza motriz, calefacción y alumbrado general obtenidos por medio de la entonces reciente electricidad. También da detalles de las diferentes secciones que poseía: el taller de construcción de marcos de hierro ${ }^{36}$, la sección de ebanistería, la de tablaje, que se encargaba de la confección de tablas armónicas, clavijeros, etcétera, la de confección de cuerdas y bordones, que utilizaba una máquina eléctrica especial de importación alemana que daba mayor rapidez y seguridad al proceso, y otras como las de encordadores, preparación de mecanismos y martillos -no menciona si éstos son fabricados allí o se importan por piezas en fábricas europeas especializadas, como sucedía en otras muchas fábricas españolas de esa época)- "finisores"37 o teclados -donde incluso se trabaja el marfil-.

Ortiz \& Cussó contaba además, por aquel entonces, con empresas secundarias relacionadas indirectamente con la facturación de pianos, lo que constata su magnitud y poderío. En la parte alta de su edificio, esta empresa poseía un secadero de maderas donde se procedía a la preparación de maderas de todas clases: pino, pinabete, abeto, chopo, álamo, haya, castaño, carpe u hojaranzo, tulipia, caoba, palisandro, ébano, cedro, sicomoro, nogal, tilo americano y otras. Algunas de estas exóticas especies de madera implicarían necesariamente unas fluidas relaciones comerciales con colonias africanas, americanas o asiáticas -controladas por otros países europeos-, o con EE.UU., pues dadas las fechas en las que se publica el artículo (1900), España ya había perdido su antigua hegemonía colonial de ultramar ${ }^{38}$. Ortiz \& Cussó disponía también de una fundición de hierro, ubicada en los arrabales de Barcelona según el artículo citado, donde se moldeaban los marcos de hierro de los pianos, significativa muestra de su importancia empresarial, e indicativo, asimismo, de la cantidad de trabajadores especializados con los que contaría esta fábrica hacia principios de siglo.

La empresa seguía ya por entonces un sistema de fabricación moderno basado en la "cadena de montaje", y sus instrumentos se fundamentaban en el mecánicamente seguro y fiable patrón de construcción americano (Steinway). Ortiz \& Cussó producía ya únicamente dos tipos de pianos, lo mismo que prácticamente el resto de fábricas españolas, el piano derecho -así aparece denominado el piano vertical en el artículo-, mayoritariamente utilizado por ser más económico y funcional, y el de cola, empleado casi exclusivamente para el ejercicio profesional.

36 Cuya incorporación al instrumento -descrita en el texto reproducido en la página precedente, procedente del artículo "La fabricación española de pianos", aparecido en el Boletín Musical de Valencia n ${ }^{\circ} 225$ (1900)- favorecerá, por una parte la consistencia y solidez general del instrumento, pero también posibilita la utilización de bordones entorchados más gruesos y cortos (graves) cuya tensión hubiera quebrado el marco de madera utilizado hasta entonces. El uso de bordones más gruesos y menos largos posibilita la reducción del tamaño de la caja, y por tanto facilita la incorporación de un piano de menores dimensiones al uso doméstico.

37 Este término, que no aparece en el Diccionario de la Real Academia Española (vigésima segunda edición. Madrid, Espasa Calpe, 2001), probablemente aluda a la palabra "finir" (finalizar, acabar), que sí recoge el $1^{\circ}$ vol. de la citada obra en su p. 1061. Si es así, la función de los finisores en el proceso de facturación de pianos podría equivaler a la de elaboración de "acabados" en una empresa actual de fabricación de productos (?).

38 La pérdida de colonias españolas había ido produciéndose a lo largo del siglo XIX pero, como es bien conocido, fue en 1898, con el estallido de la Guerra Hispano-estadounidense, cuando culminó ese proceso que tuvo como consecuencia el paso de Cuba, Puerto Rico y las Filipinas a manos de EE.UU. 
No obstante, las diferencias existentes entre empresas nacionales más locales y la firma Ortiz \& Cussó por la misma época eran abismales, tanto en el ámbito constructivo como en el comercial (también existieron otras fábricas importantes de pianos entonces en Barcelona, pues fue posiblemente la ciudad española más expansionada empresarialmente durante los años del cambio al siglo XX).
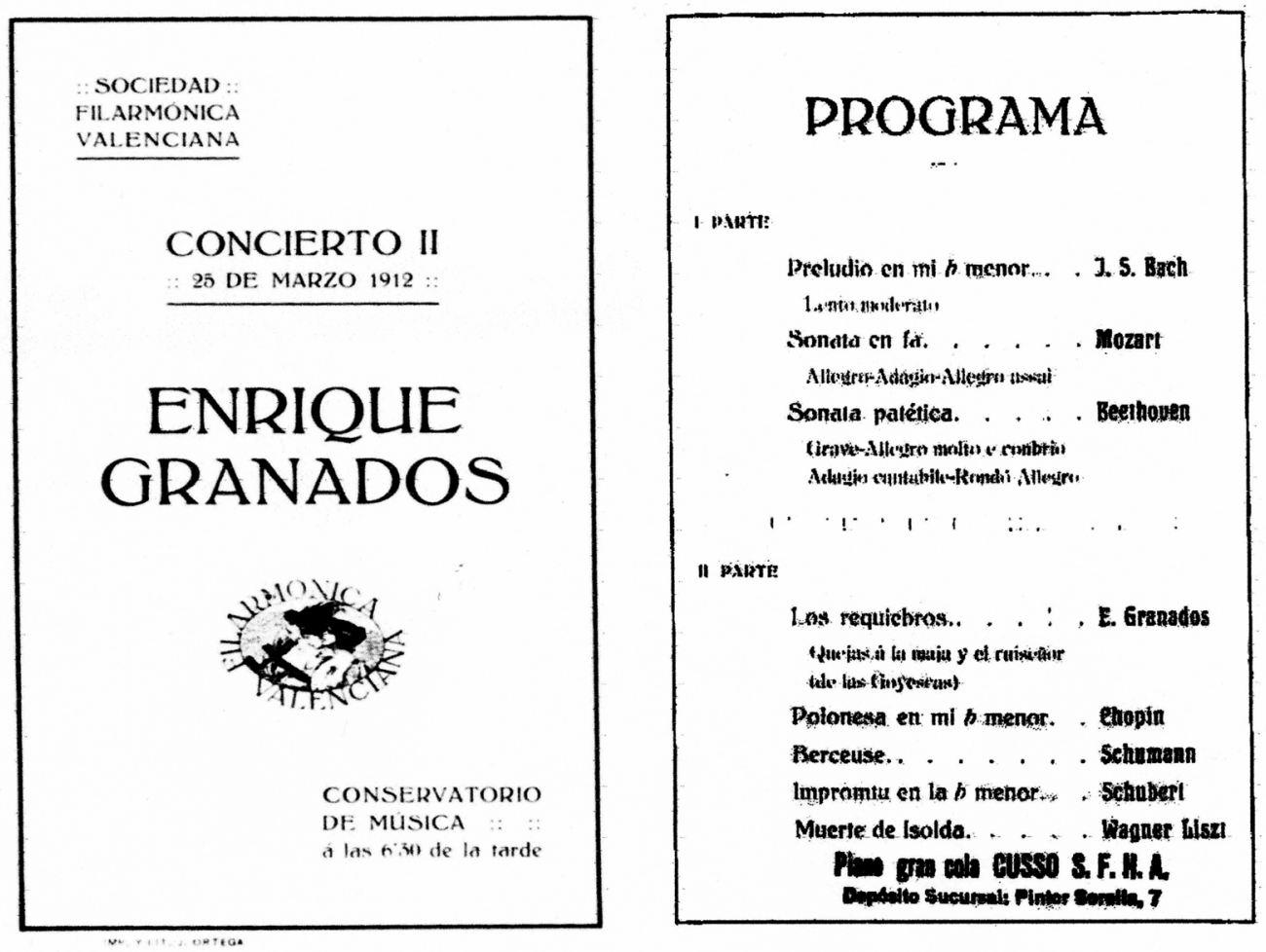

Programa del concierto ofrecido por Enrique Granados para la Sociedad Filarmónica de Valencia en marzo de 1912, donde se hace constar que el artista tocó sobre un piano Cussó S.F.H.A.

(Cussó Sociedad Franco-Hispano-Americana).

En el programa precedente se constata la utilización de un piano de gran cola Cussó SFHA (Cussó Sociedad Franco- Hispano-Americana) que había sido cedido por su distribuidor valenciano, entonces, Eusebio Ventura ${ }^{39}$. Cussó SFHA, nombre que utilizaba por entonces la antigua casa barcelonesa Ortiz \& Cussó, ya se había convertido en multinacional y se había expandido enormemente hacia 1915, y cubría, al parecer, gran parte del mercado nacional de instrumentos.

39 La Filarmónica valenciana ofrecía sus conciertos en el Salón de Actos del Conservatorio de Música, que se encontraba en la Plaza de San Esteban (actualmente sede del Conservatorio Profesional de Música de Valencia). El piano que se utilizaba cuando los intérpretes eran importantes (caso de Enrique Granados) solía ser prestado por algún comercio de la ciudad; así, dicha tienda se hacía propaganda y también se posibilitaba la intervención de un piano de más calidad en esas determinadas ocasiones. 
Arthur Rubinstein también tocó un piano Cussó SFHA en los cuatro recitales que ofreció para la Sociedad Filarmónica de Valencia en diciembre de 1916. La empresa barcelonesa -probablemente por mediación de su intermediario en la ciudad, el citado Eusebio Ventura- consiguió que se incluyera en dichos programas una nota, a modo de propaganda, donde el prestigioso pianista elogiaba sus instrumentos, mostrando ya así unas técnicas de publicidad bastante sofisticadas para la época.

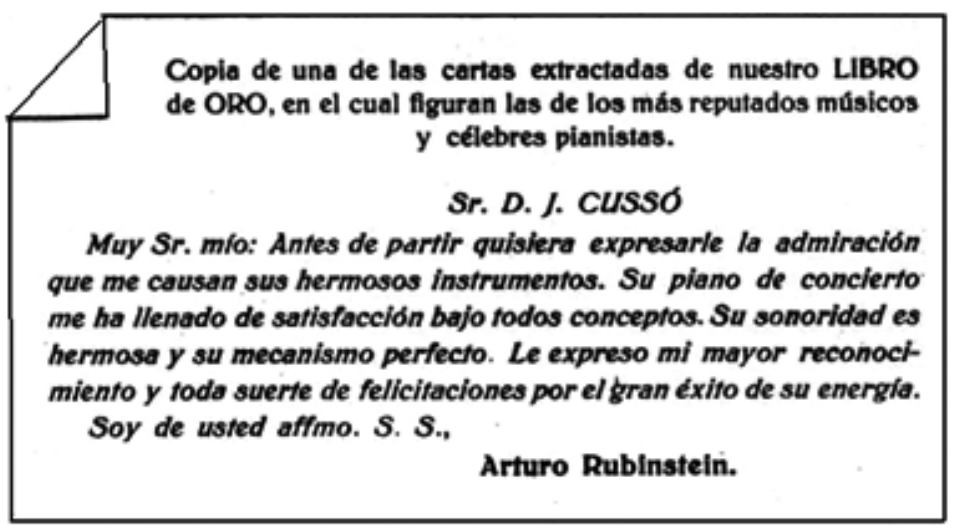

Nota incluida en los programas que Arthur Rubinstein dio en Valencia los días

$$
16,17,18 \text { y } 19 \text { de diciembre de } 1916 .
$$

En Valencia, ese impulso económico general que experimentó toda España en la década de 1900 se materializó con la celebración de la Exposición Regional Valenciana de 1909, que se prolongaría un año más tarde como Exposición Nacional de Valencia (1910). En su Catálogo General de Expositores vuelven a hallarse datos sobre el funcionamiento de algunas empresas existentes en 1883 que habían evolucionado: Manufactura de pianos Gómez (antes Gómez é hijo), y Mariano Carreres.

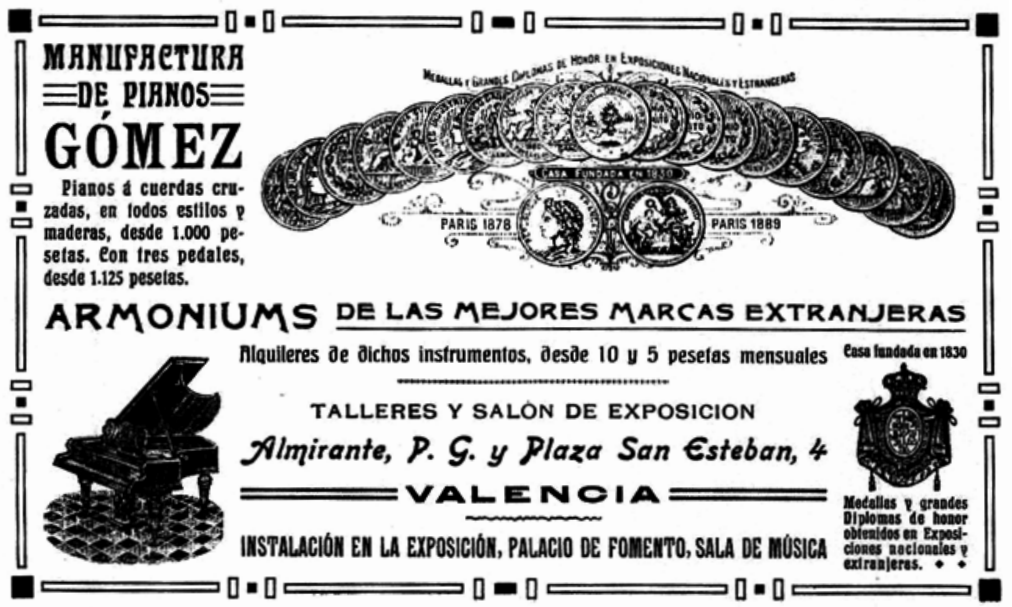

Anuncio de la empresa Manufactura de Pianos Gómez [antes Gómez è hijo]

(Catálogo Oficial de Expositores. Exposición Regional Valenciana de 1909) 
A juzgar por el anuncio insertado en el mencionado catálogo (reproducido arriba), Manufactura de pianos Gómez había crecido considerablemente hacia 1909. Lo constata la cantidad de galardones que exhibe en su publicidad -según puede descifrarse en las medallas insertadas, los premios eran tanto valencianos (de la Sociedad Económica de Amigos del País, del Ateneo Casino [Mercantil?]), como “extranjeros" (Exposiciones Universales de París de 1878 y 1889)-, los dos domicilios sociales que ya poseía en la ciudad por esas fechas (Almirante, P. G. ${ }^{40}$ y su antigua sede de la Plaza de San Esteban, 4 -que podrían corresponder uno al comercio propiamente dicho, y otro a los talleres-), el hecho de continuar siendo empresa proveedora de la Casa Real española (aparece su escudo en el anuncio), la variedad y precio de los modelos que produce y vende (con cuerdas cruzadas y dos o tres pedales), y el hecho de que hayan ampliado su versatilidad comercial y, por entonces, no sólo vendan los instrumentos fabricados, sino que también los alquilen. Asimismo, en el caso de los armonios, anuncia que dispone de "marcas extranjeras" (posiblemente francesas y/o norteamericanas), lo que confirma el desarrollo comercial alcanzado por los antiguos talleres de Pedro Gómez en la década de 1900.

Mariano Carreres insertaba un anuncio más modesto en dicho catálogo, a pesar de que, finalmente, lograría obtener Diploma de Honor y Medalla de Oro en aquella Exposición Regional Valenciana de 1909. En la propaganda se hacía constar que Carreres todavía construía pianos con una disposición de cuerdas en vertical, probablemente más económicos -las empresas importantes habían desechado hacia finales del siglo XIX dicho sistema-, aunque se puntualiza que también los fabricaba con cuerdas cruzadas - posiblemente en menor cantidad, pero mencionándolo el grado de "modernidad" de sus patrones de construcción parece menos cuestionable-. Además, se pone de relieve que dicha empresa ampliaba entonces sus competencias hacia la afinación/reparación de instrumentos, y el mercado de segunda mano (accesorios, etc.).

Pero, además de las dos citadas empresas locales ya decimonónicas, concurrió a dicha exposición otra firma de reciente fundación, Rodrigo Ten y $C^{a}$, aparecida en 1903, que ya se revelaba en el catálogo como una fábrica local en clara expansión. En su anuncio ya

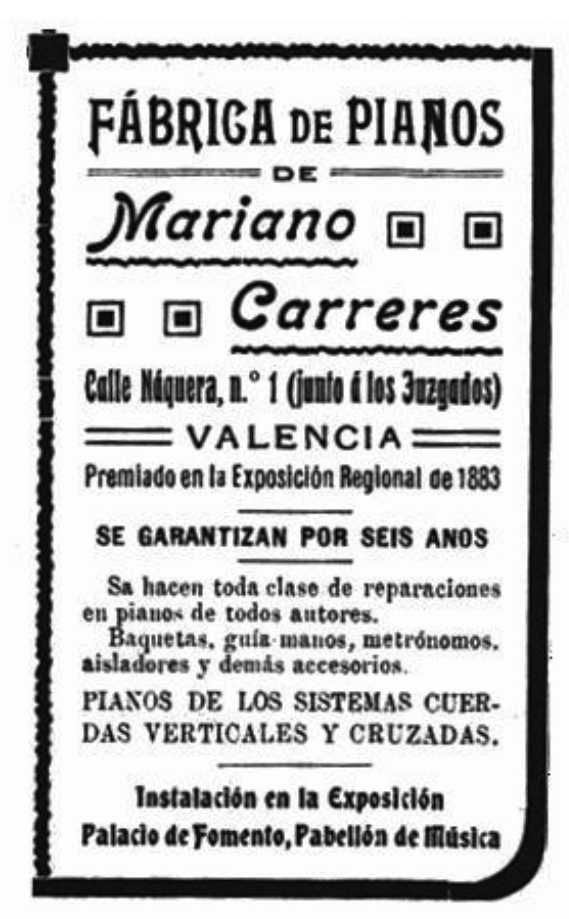

Anuncio de la fábrica de pianos de Mariano Carreres. (Catálogo Oficial de Expositores. Exposición Regional Valenciana de 1909)

40 El confuso segundo domicilio que se da en el anuncio de Manufactura de Pianos Gómez, "Almirante, P. G.", aunque podría referirse a algún local sito en la calle del Almirante, próxima a la plaza de San Esteban, donde se ubicaba su otro edificio, también puede aludir al Palacio de los Almirantes de Aragón, también conocido como Palacio de los Marqueses de Guadalés (de ahí las siglas "P. G:" que figuran en la publicidad), hoy sede de la Consellería de Hacienda. Es más, el Palacio de los Marqueses de Guadalés es el único domicilio social de la empresa de Pedro Gómez que se da en:-MAs, Manuel dir. y prod.: "Gómez Peralta, Pedro", en Gran Enciclopedia de la Región Valenciana. Valencia, Graphic 3, 1973, vol. 5, p. 129. 
no se menciona que se dedique también a la construcción de órganos y armonios, como sucedía con la anteriormente mencionada Gómez é hijo; por tanto, posiblemente ya se tratara de una factoría especializada solamente en la construcción y el montaje de pianos.

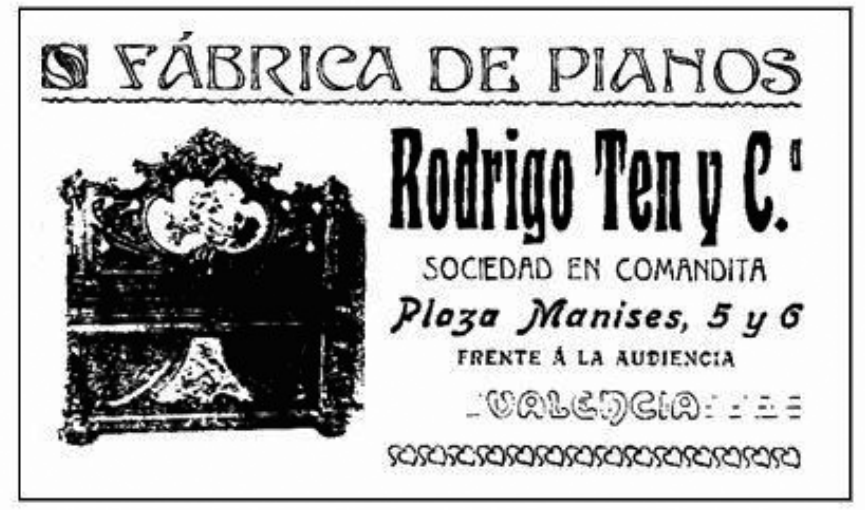

Anuncio de la fábrica de pianos Rodrigo, Ten y Cía.

(Catálogo Oficial de Expositores. Exposición Regional Valenciana de 1909)

Su publicidad es más ampulosa y agresiva que la expuesta por las otras dos fábricas valencianas, e incluye una minuciosa descripción de sus medios empresariales: Rodrigo Ten y $C^{a}$ exporta al resto de España y a Ultramar, construye (o monta) pianos verticales de cuerdas cruzadas siguiendo el sistema norteamericano "en cuya fabricación han adquirido tanta perfección, que compiten con ventaja á todas las marcas nacionales y extranjeras, habiendo merecido altas distinciones, como son: Medalla de Oro en la Exposición Internacional de Madrid de 1907 y en la Hispano Francesa [de Zaragoza] de 1908”.

También se cita que la empresa regaló al monarca español, Alfonso XIII, con motivo de su visita a Valencia en 1909 para inaugurar la citada Exposición, un "pianito" de reducidas dimensiones que contaba con tan sólo cuatro octavas, y su precio era de 90 céntimos (!). Este instrumento, especialmente diseñado para ser utilizado por un niño, tenía como destinatario al entonces Príncipe de Asturias, D. Alfonso de Borbón y Battenberg41.

Asimismo, el texto que acompañaba al anuncio incluido en el Catálogo de la Exposición Regional de 1909 destacaba, por una parte la ampulosidad de los muebles modernistas de los pianos $\mathrm{y}$, por otra, la

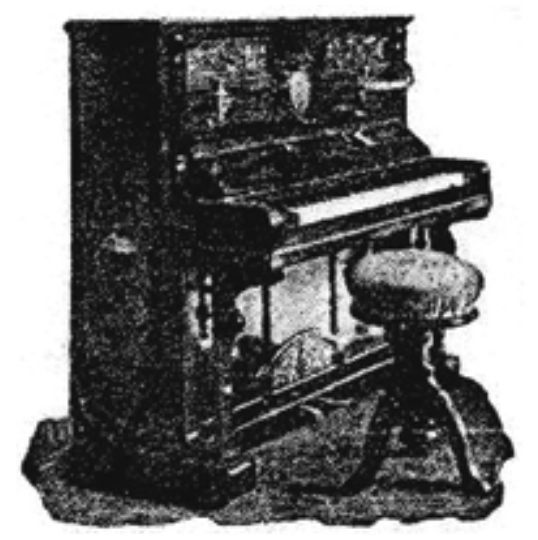

"Pianito" que Rodrigo, Ten y Cía. regaló a Alfonso XIII en 1909 para uso del Príncipe de Asturias

41 Alfonso de Borbón y Battenberg (*1907; † 1938) y su hermano Gonzalo (*1914; † 1934) eran hemofílicos, y el tercero de los hijos de Alfonso XIII, Jaime (*1908; $\uparrow 1975)$, sordomudo; por ello fue D. Juan (*1913; $\uparrow 1993)$, padre del actual monarca Juan Carlos I, el heredero entonces de la dinastía Borbón. 
sonoridad y capacidad de matización de sus instrumentos, cualidades que, según la propia firma exponía, provocaron que "casi todos los Conciertos que [dieron] en Valencia pianistas eminentes, [fueran efectuados] en los pianos de esta Casa". Sin embargo, sería la primera faceta la que, a tenor de la publicidad que insertaba alrededor de 1915 en la prensa periódica musical valenciana, caracterizaría a Rodrigo Ten y $C^{a}$ en fechas posteriores, pues incluso se ofrecía por entonces, además de como constructor de pianos, como refinado ebanista (!).

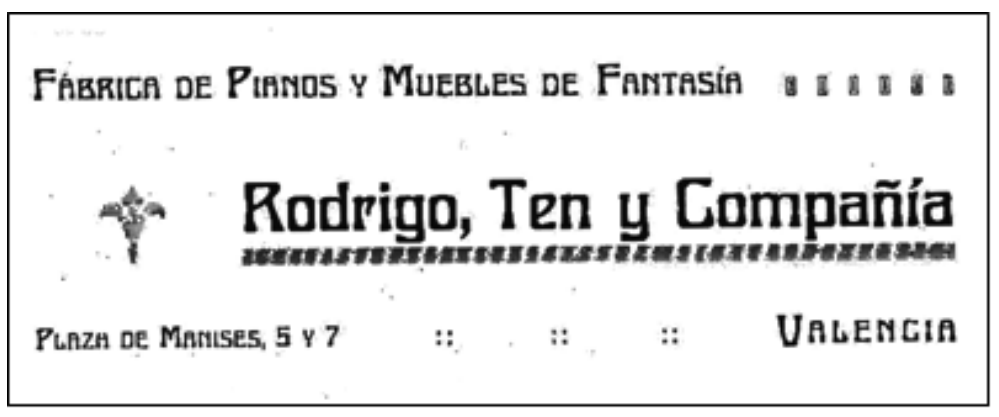

Anuncio de Rodrigo, Ten y Cía. hacia 1915

Esta especial particularidad se debía a que la tarea de los pequeños fabricantes locales tendía a limitarse por entonces al montaje de pianos verticales "económicos" que satisficieran la enorme demanda que la burguesía media había generado desde principios del nuevo siglo. Esos instrumentos estaban provistos de bonitos y trabajados muebles, pero poseían mecanismos importados construidos en serie, procedentes generalmente de fábricas alemanas especializadas en su construcción como Renner o Schwander ${ }^{42}$.

Rodrigo, Ten y Cia, siguió funcionando hasta los primeros años de la década de 1970, y tuvo su sede en la plaza de Manises, muy cerca del Conservatorio de música de la ciudad, y dentro del casco antiguo de Valencia. Los locales de las otras fábricas de pianos valencianas estaban muy próximos: Gómez seguía conservando aún sus dos sedes decimonónicas, una en la Plaza de San Esteban (junto al conservatorio de la ciudad) y la otra en "Almirante P. G." (que podría referirse, bien a la calle del Almirante, bien al palacio de Guadalés o del Almirante sito en la plaza de Nápoles y Sicilia); y Carreres permanecía en su dirección de la calle de Náquera, junto a los Juzgados. Por tanto, la ubicación de todas estas fábricas/taller todavía acusaba en el siglo XX una proximidad que sugería una heredada distribución "gremial" ( $c f r$. plano adjunto).

Pero la función de "productor/montador" de pianos que estas firmas poseían desde fines del siglo XIX se fue decantando hacia el mercado de segunda mano progresivamente, imitando una labor que a

42 Louis Renner patentó el mecanismo vertical en 1842 para la compañía constructora de pianos Bösendorfer; por ello, el mecanismo del piano vertical se denomina "mecánica Renner" aún en nuestros días. Renner se estableció como fabricante independiente en 1882 en Sttutgart (Alemania) y se dedicó a la producción de mecanismos y repuestos para pianos con el nombre de Hammer Heads \& Piano supplies. La especialización en la fabricación de mecanismos verticales que caracteriza a las empresas Renner o Schwander hizo que diferentes fábricas de pianos construyeran sus modelos verticales insertándoles simplemente mecanismos de éstas u otras empresas similares. Por ello, aunque algunos pianos verticales cuenten con una marca de fabricación, su mecanismo interno procede, en muchas ocasiones, de este tipo de empresas especializadas únicamente en la construcción de mecanismos. 


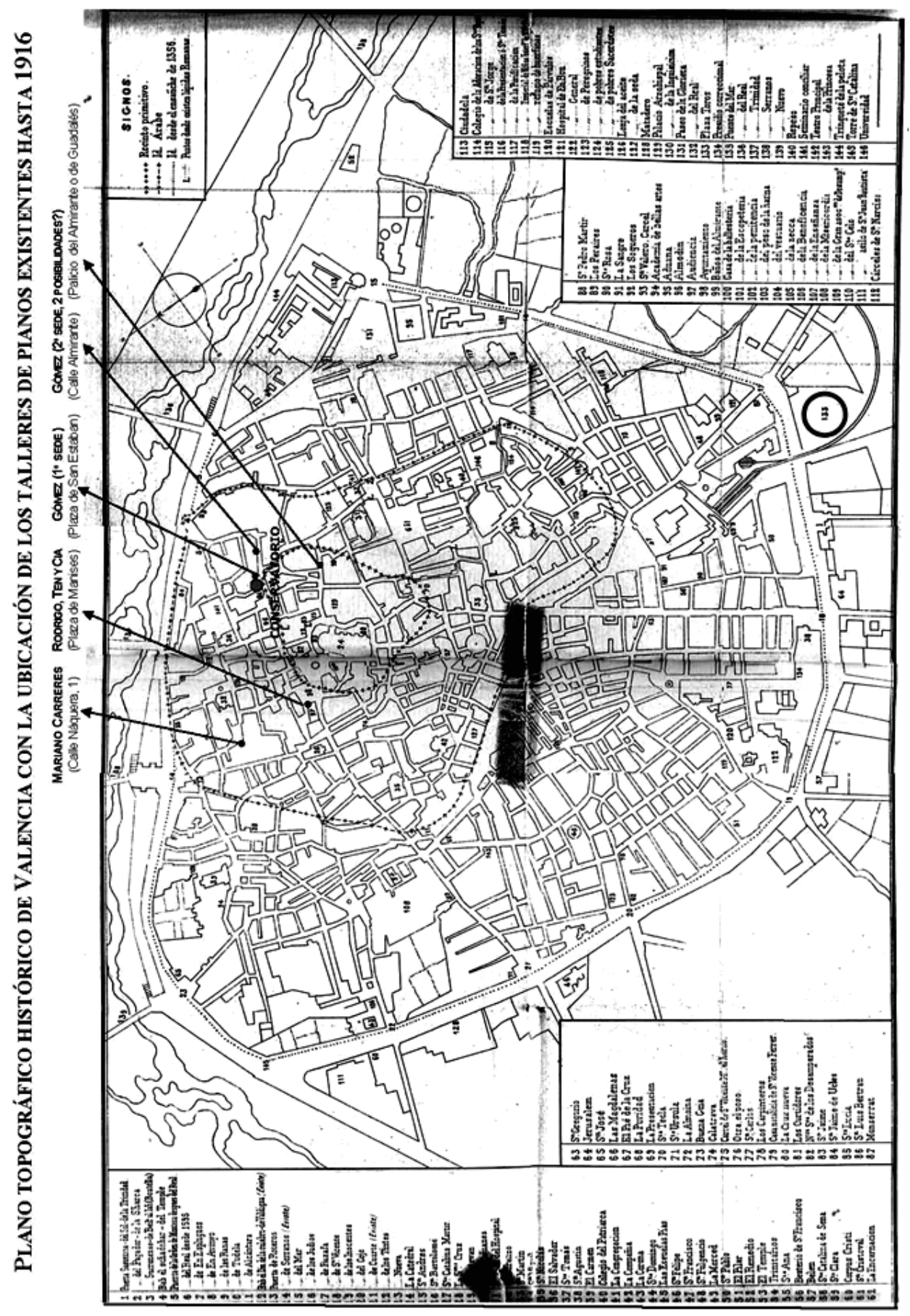

Mapa de Valencia extraído de -Cruilles, Vicente Salvador y Monserrat, Marques de: Guía urbana de Valencia antigua y moderna dedicada a la Sociedad de Amigos del País. Valencia, José Rius, 1876. 
partir de entonces desempeñaron otras empresas centradas exclusivamente en la afinación y reparación de pianos creadas hacia 1910 para cubrir las expectativas de una sociedad valenciana que incrementaba su demanda de técnicos. Esta nueva labor sería principalmente habilitar y poner a la venta "nuevos" pianos compuestos a partir de mecanismos y elementos procedentes de viejos instrumentos. Los nuevos "talleres" -ya no podían conceptuarse como fábricas-, proliferaron en Valencia desde 1910 hasta prácticamente el último cuarto del siglo XX -algunos, como Pianos Roca (Algemesí, Valencia), siguen funcionando en la actualidad ${ }^{43}$.

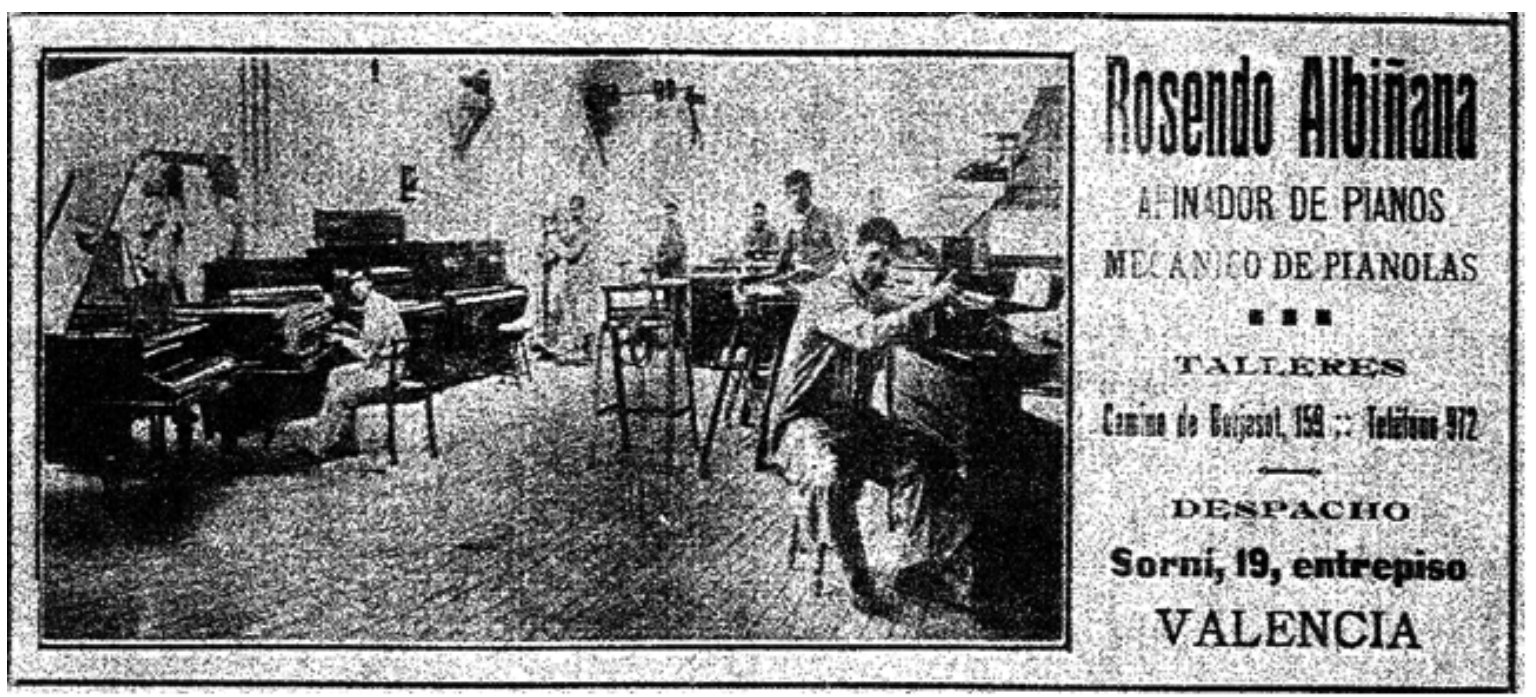

Anuncio del taller de pianos de Rosendo Albiñana, hacia 1915

El anuncio precedente, que el afinador y reparador de pianos y pianolas Rosendo Albiñana hacía publicar en la revista musical valenciana "Mundial Música” alrededor de 1915 puede servir de ejemplo del nuevo cometido de los talleres de pianos valencianos del siglo XX. En la fotografía precedente se pone en evidencia que este tipo de talleres eran, en realidad, pequeñas empresas cuya labor era, además de reparar y afinar instrumentos -estos trabajos debían realizarse generalmente desplazándose el operario a los domicilios particulares que solicitaran sus servicios, como sucede actualmente-, transportarlos al taller, reformarlos y, en la mayoría de casos, revenderlos como mercancía de segunda mano -cinco de los ocho instrumentos que aparecen en la imagen no se encuentran "en exposición", están siendo "rehabilitados" por los empleados-. Asimismo, destacan en la imagen la amplitud de los locales -que ya se encuentran fuera de la ciudad (en el Camino de Burjasot, 159) aunque el "despacho" permanezca en el centro del casco urbano (calle de Sorní, 19) para no distanciarse de sus competidores-

43 En la publicidad online que la propia firma ofrece actualmente (en la dirección pianosroca.com), consta que dicha empresa familiar fue fundada por el artesano [calificativo que se usa textualmente en su propaganda] D. Antonio Sabater en 1940. Actualmente ofrecen los siguientes servicios: venta de pianos acústicos (Yamaha, Kawai, Atlas, y otras marcas "adheridas a los citados fabricantes"); transporte, banqueta, afinación y 15 años de garantía [postventa]; instalación del Kit sistema silencioso; posibilidad de compra a distancia; afinación de pianos; restauración integral de pianos, pianolas y armóniums neumáticos; servicios técnico y de asesoramiento; y alquiler de pianos para conciertos. 
y el número de empleados que aparecen trabajando. Además, Rosendo Albiñana ya se anuncia como mecánico de pianolas, dando constancia así de la gran difusión que este tipo de instrumentos mecánicos alcanzó en su tiempo como elemento de entretenimiento social, precediendo en su función a la después cumplida por algunos aparatos como el tocadiscos o la televisión.

La no muy numerosa pero notable fabricación autóctona de pianos, por tanto, se desarrolló en Valencia capital en torno a 1830 y las primeras décadas del siglo XX, principalmente. Surgió en un principio para abastecer, fundamentalmente, el mercado local, pero experimentó una clara expansión hacia el mercado nacional durante el período entre siglos (Gómez é hijo y Rodrigo, Ten y Cia), años en los cuales los pianos valencianos alcanzarían su mayor reconocimiento social y comercial. Dicho auge se encuentra reflejado, por una parte, en los premios y galardones obtenidos por los instrumentos salidos de esos talleres durante aquellos años; por otra, por el hecho de comercializar entonces sus productos en el mercado nacional y de "ultramar", tal y como constata en la publicidad de dichas empresas conservada en la actualidad ${ }^{44}$.

Pero las factorías "pianísticas" valencianas fueron evolucionando progresivamente hacia sistemas de producción más modernizados que, en cierta forma, contribuyeron a hacerle perder las señas de identidad que las habían caracterizado durante el siglo XIX. Hacia 1900 entraron a formar parte de una especial "cadena de montaje" de instrumentos (como lo hicieron, en general, otras muchas factorías españolas del gremio), por la cual se confeccionaban localmente pianos usando mecanismos y elementos fabricados por empresas extranjeras especializadas; podría decirse, por tanto, que la única parte de los instrumentos locales manufacturada verdaderamente en Valencia era el mueble (Rodrigo, Ten y Cia. $)^{45}$.

Cronologia de los Talleres de Construccion de Pianos en Valencia hasta 1930*

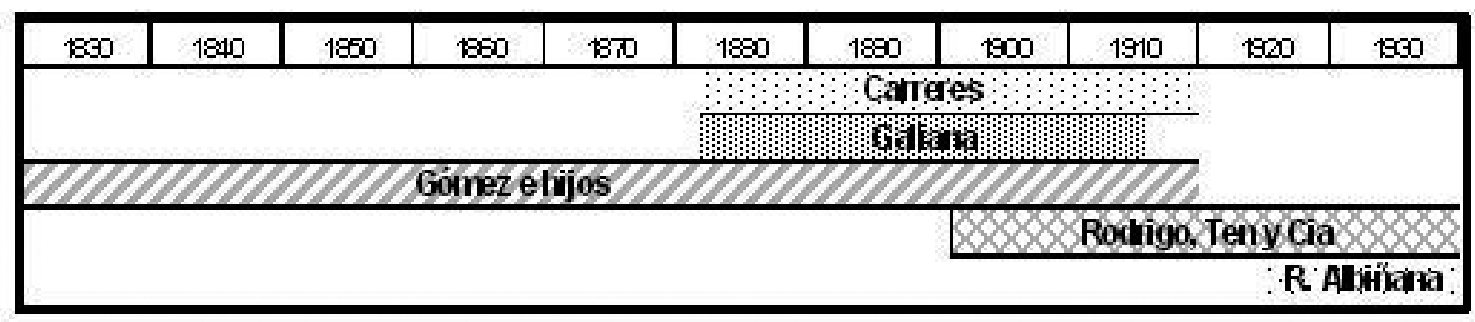

*Algunas empresas aparecen en el gráfico sin delimitar a la derecha o a la izquierda porque se desconoce la fecha de su fundación y/o de su desaparición.

44 De hecho, la circunstancia de que expusiera sus productos en las exposiciones Regional Valenciana de 1909 y Nacional de Valencia de 1910 Manuel Durá Argente, titular de una empresa encargada de fabricar bordones para instrumentos musicales, es un indicativo más del auge que cobró la construcción de pianos en Valencia a principios de siglo. Es de suponer que mucha de su producción se dedicaría a la elaboración de bordones para guitarra, ya que la fabricación valenciana de este tipo de instrumentos era bastante importante en aquella época, pero si aparece en los catálogos de las exposiciones citadas como "fabricante de bordones para instrumentos musicales" -incluso obtiene por ello la medalla de oro de la Exposición Regional Valenciana de 1909-, posiblemente también confeccionara bordones para piano.

45 Algo similar a lo que hacían algunos "organeros" (que compraban tubos de estaño en el extranjero reduciendo así su trabajo) cuya tarea se limitaba prácticamente a "armonizar" las piezas montadas (en cierta forma, podría parangonarse a lo que hacen actualmente algunos informáticos con los ordenadores "clónicos” montados a partir de piezas sueltas de distintas procedencias). 
Finalmente, y en casi todos los casos, su categoría de fábrica de pianos se perdería progresiva y definitivamente cuando, además de dedicarse a "montar" instrumentos con mecanismos extranjeros, se centraron preferentemente en reformar y habilitar pianos viejos para revenderlos (Rosendo Albiñana). Con ello pasarían, primeramente, a ser competidores del grueso de empresas valencianas que ya desde mediados del siglo XIX habían desempeñado exclusivamente una función comercial de distribución y compra/venta de pianos (como Turell o Antonio Sánchez Ferrís que, aunque los vendían y reparaban, nunca se habían dedicado a construirlos -vid. al lado y a continuación la reproducción de los anuncios

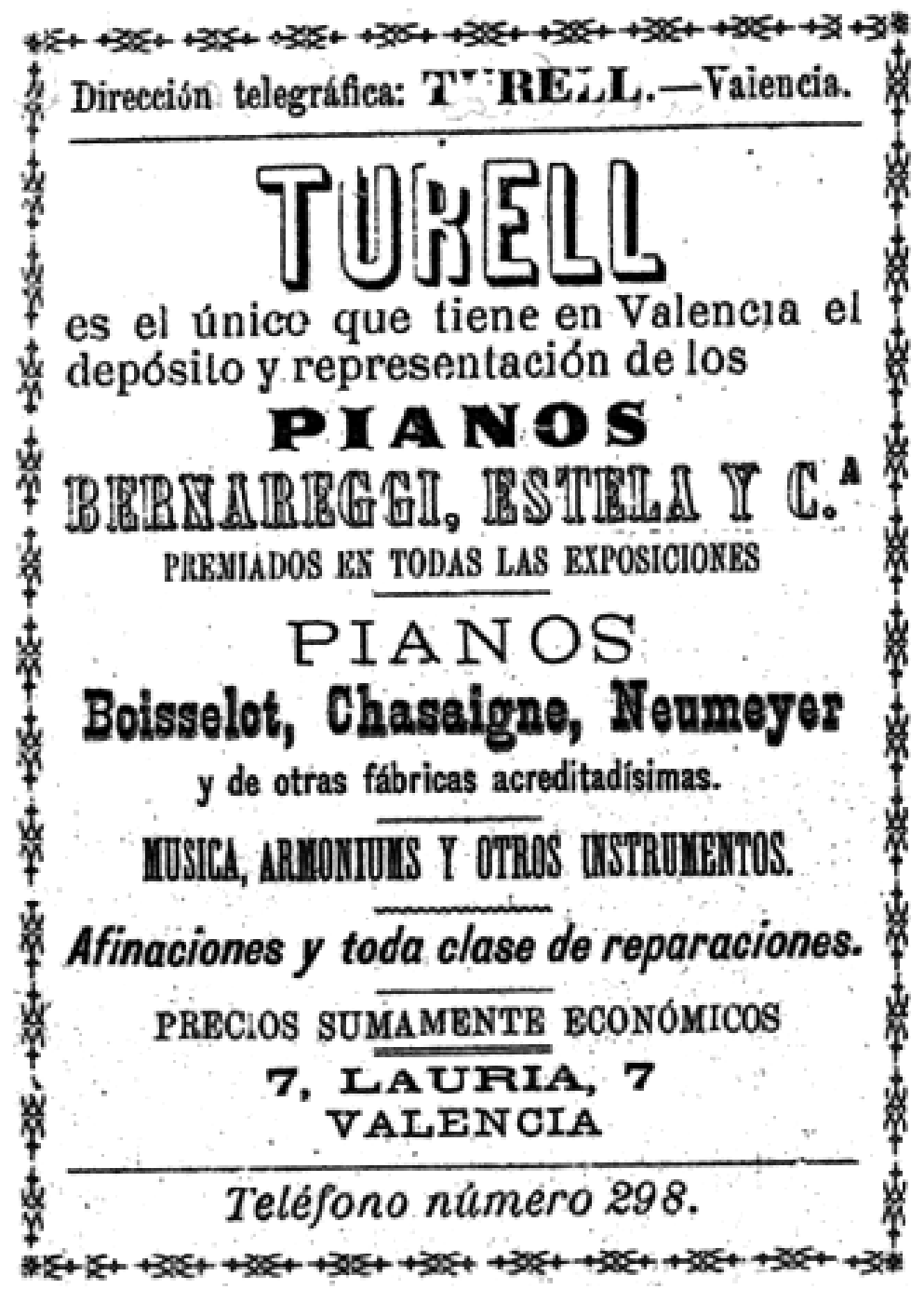

Anuncio del comercio Turell en los años del cambio hacia el siglo XX. 
de esas dos casas-); después, o desaparecerían definitivamente, o ya comenzarían a funcionar como lo hacen los comercios musicales actuales, que ofertan el servicio de afinación/reparación de pianos como otro de sus muchos cometidos (además de la venta de partituras, instrumentos, accesorios musicales y material didáctico).

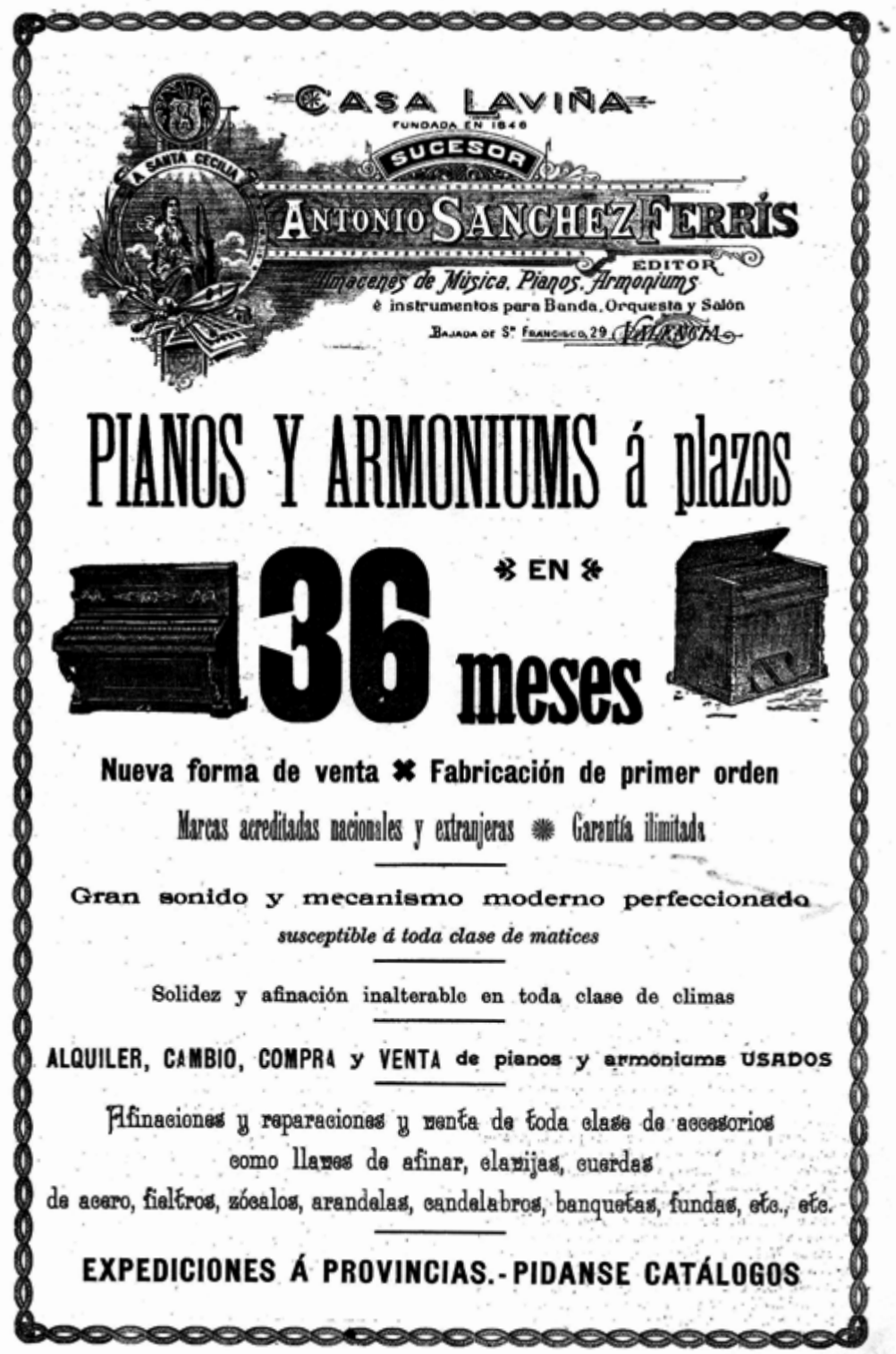

Propaganda de la empresa Sánchez Ferrís durante el período de tránsito al siglo XX.

Tanto en este anuncio como en el de "Casa Turell" insertado en la página anterior, se observa que ambas firmas comerciales, además de vender pianos, se ofrecían por entonces como afinadores/reparadores de pianos. 
